\title{
Flue Gas Conditioning for Improved Particle Collection in Electrostatic Precipitators
}

\author{
Second Topical Report
}

Results of Bench-Scale Screening of Additives

Contract No. DE-AC22-91PC90364

Prepared for:

U.S. Department of Energy

Pittsburgh Energy Technology Center Pittsburgh, PA 15236

Project Officer: Mr. Thomas Brown

Prepared by

Michael D. Durham, Ph.D.

\begin{abstract}
ADA Technologies, Inc. 304 Inverness Way So. Englewood, CO 80112
\end{abstract}

(303) $792-5615$

ADA Report 4300-93-T2

August 13, 1993 


\section{Table of Contents}

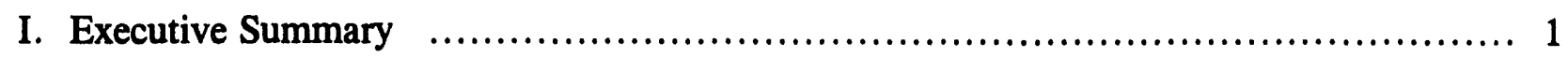

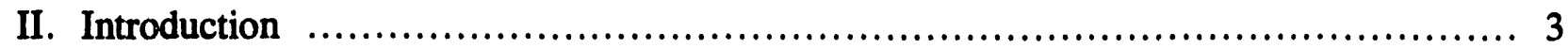

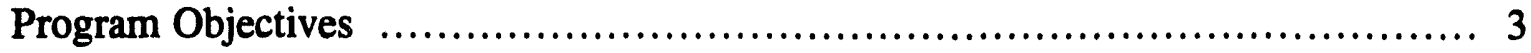

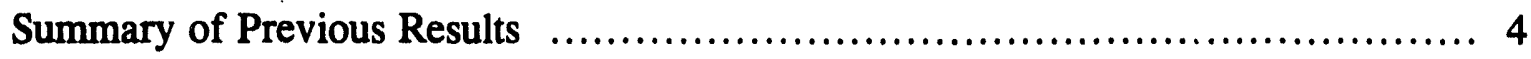

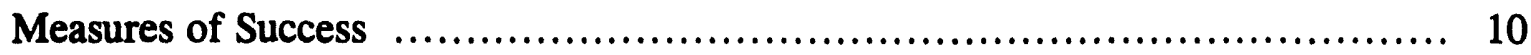

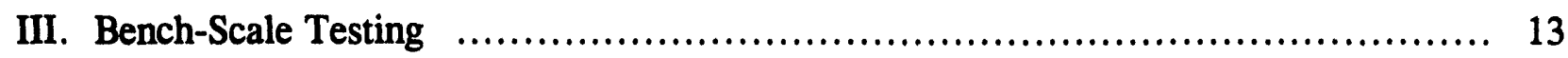

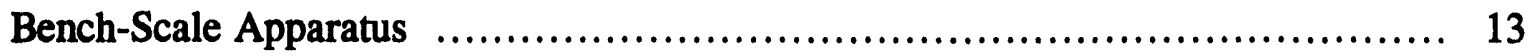

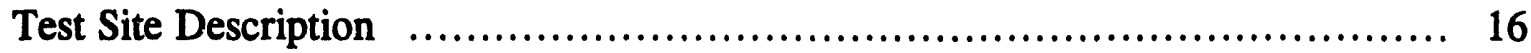

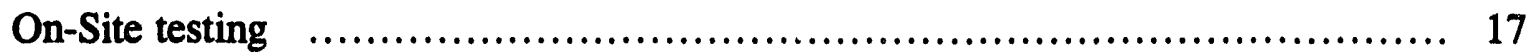

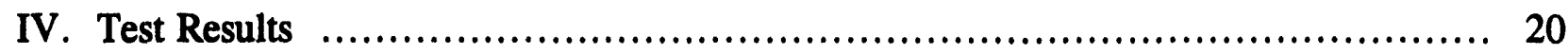

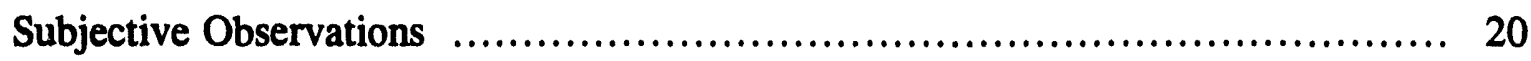

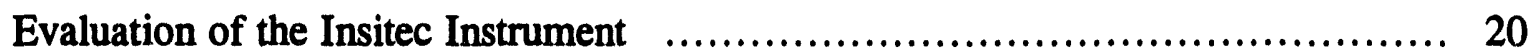

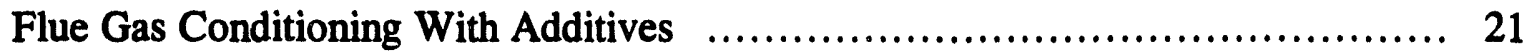

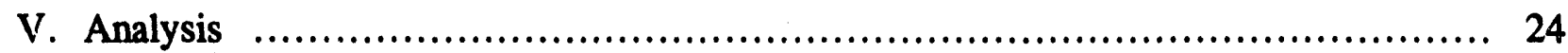

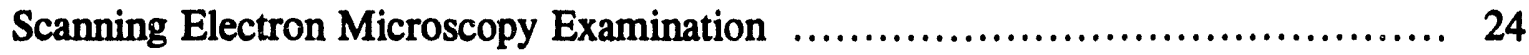

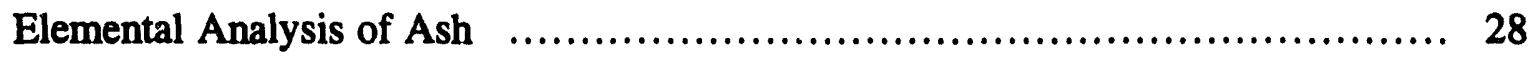

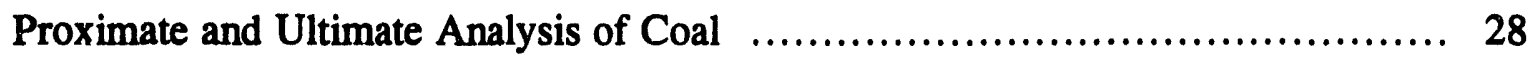

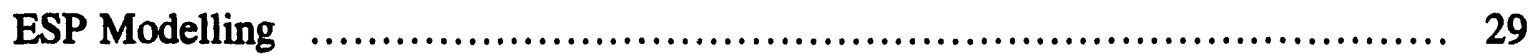

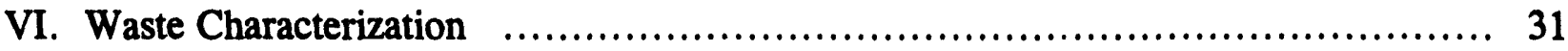

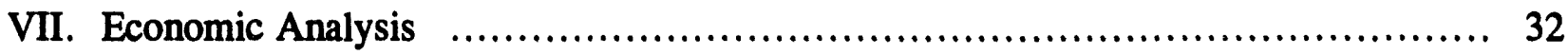

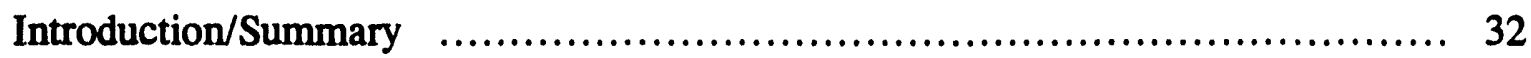

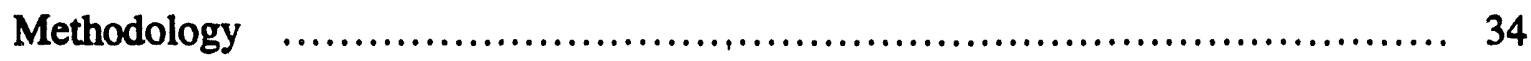

Injection System Process Design and Operating Parameters $\ldots \ldots \ldots \ldots \ldots \ldots \ldots \ldots \ldots . \ldots . \ldots 36$

Economic Results ............................................................. 39

Recommendations for Future Testing and Economic Analysis .................. 42

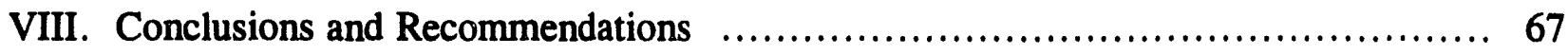




\section{Executive Summary}

ADA Technologies, Inc. (ADA) has completed the bench-scale testing phase of a program to evaluate additives that will improve the collection of fine particles in electrostatic precipitators (ESPs). A bench-scale ESP was installed at the Consolidation Coal Company (CONSOL) combustion research and development facility in Library, PA in order to conduct the evaluation. During a two-week test, four candidate additives were injected into the flue gas ahead of a 100 acfm ESP to determine the effect on fly ash collectability. Two additives were found to reduce the emissions from the ESP. Table I-1 summarizes the results.

Table I-1. Summary of Bench-Scale Testing

\begin{tabular}{|cccccc||}
\hline $\begin{array}{c}\text { Test } \\
\text { Date }\end{array}$ & $\begin{array}{c}\text { Test } \\
\text { Condition }\end{array}$ & $\begin{array}{c}\text { Collection } \\
\text { Efficiency }\end{array}$ & $\begin{array}{c}\text { Particle } \\
\text { Penetration }\end{array}$ & $\begin{array}{c}\text { Emission } \\
\text { Reduction }\end{array}$ & $\begin{array}{c}\text { Test } \\
\text { Temperature }\end{array}$ \\
\hline $5 / 13$ & Baseline & $40.4 \%$ & $59.6 \%$ & & $307^{\circ} \mathrm{F}$ \\
$5 / 13$ & Additive C & $50.4 \%$ & $49.6 \%$ & $16.8 \%$ & $308^{\circ} \mathrm{F}$ \\
$5 / 14$ & Baseline & $34.4 \%$ & $65.5 \%$ & & $305^{\circ} \mathrm{F}$ \\
$5 / 14$ & Additive A & $28.9 \%$ & $71.1 \%$ & $-8.5 \%$ & $307^{\circ} \mathrm{F}$ \\
$5 / 14$ & Baseline & $42.8 \%$ & $57.2 \%$ & & $300^{\circ} \mathrm{F}$ \\
$5 / 14$ & Additive B & $44.1 \%$ & $55.9 \%$ & $2.3 \%$ & $305^{\circ} \mathrm{F}$ \\
$5 / 14$ & Additive D & $52.4 \%$ & $47.6 \%$ & $16.8 \%$ & $287^{\circ} \mathrm{F}$ \\
\hline $5 / 19 *$ & Baseline & $64.6 \%$ & $35.4 \%$ & & $308^{\circ} \mathrm{F}$ \\
$5 / 19 *$ & Additive C & $74.3 \%$ & $25.7 \%$ & $27.4 \%$ & $307^{\circ} \mathrm{F}$ \\
\hline
\end{tabular}

* Baffle plates were added to the ESP during the second week of testing to reduce sneakage.

The bench-scale test was extremely important since it represented the first field test where the additives were evaluated in the presence of actual flue gas. Enough data was collected during the test to establish positive (and negative) correlations with the addition of additives to the flue gas. The test was successful in narrowing down the number of additives suggested for evaluation at pilot scale. Early in the program, approximately 50 additives were identified for evaluation. The work performed to date has identified two of these for testing during the final phase of the program.

Additives " $C$ " and " $D$ " performed better than initially anticipated - reducing emissions initially by $17 \%$. Emissions were reduced by $27 \%$ after the ESP was modified by the installation of baffles to minimize sneakage. In addition to the measured improvements in performance, no detrimental effects (i.e., electrode fouling) were observed in the operation of 
the ESP during the testing. The measures of success identified for the bench-scale phase of the program have been surpassed. Since the additives will affect only non-rapping reentrainment particle losses, it is expected that an even greater improvement in particle collection will be observed in larger-scale ESPs. Therefore, positive results are anticipated during the pilot-scale phase of the program and during a future full-scale demonstration test.

A preliminary economic analysis was performed to evaluate the cost of the additive process and to compare its costs against alternative means for reducing emissions from ESPs. The results show that conditioning with additive $\mathrm{C}$ at a rate of $0.05 \%$ (wt. additive to wt. fly ash) is much less expensive than adding new ESP capacity, and more cost competitive than existing chemical conditioning processes.

Preliminary chemical analysis of conditioned fly ash shows that it passes the Toxicity Characteristic Leaching Procedure criteria. 


\section{Introduction}

Electrostatic precipitators (ESP) serve as the primary air pollution control device for the majority of coal-fired utility boilers in the Eastern and Midwestern regions of the United States. Since most of these ESPs are collecting fly ash generated from medium- and highsulfur coal, they are not experiencing operational limitations which are common when treating high-resistivity particles and are performing at an efficiency that is as high as could be expected.

However, there are indications that the collection efficiency could be improved with flue gas conditioning. Conditioning is commonly used for solving operational problems associated with high-resistivity dusts. The purpose of conditioning for low- and moderateresistivity applications is to increase the cohesive characteristics of the dust. Flue gas conditioning that increases particle cohesion has the potential to improve overall collection efficiency because a large percentage of particulate emissions from a well-performing ESP is due to reentrainment. Improved ESP performance should result if particle reentrainment could be reduced by making the particles more cohesive. This could produce a significant reduction in emissions from an ESP from the following mechanisms:

- Reduced erosion-type reentrainment

- $\quad$ Reduced rapping emissions

- Reduced hopper reentrainment

- Increased agglomeration of fine particles

A flue gas conditioning system would have several advantages as a retrofit technology for ESPs. Because it would require no modifications to the ESP, it would be very cost effective. Flue gas conditioning systems that are currently available are relatively simple and can be applied to almost any ESP. The installation would require minimal downtime of the boiler. Finally, it could also be used on new ESP designs to provide high collection efficiency with a reduced collection area.

\section{Program Objectives}

The purpose of this research program is to identify and evaluate a variety of nontraditional additives capable of increasing particle cohesion which could be used for improving collection efficiency in an ESP. A three-phase screening process is being used to provide the 
evaluation of many additives in a logical and cost-effective manner. The three step approach involves the following experimental setups:

1. Provide a preliminary screening in the laboratory by measuring the effects of various conditioning agents on reentrainment of fly ash particles in an electric field operating at simulated flue gas conditions.

2. Evaluate the successful additives using a $100 \mathrm{acfm}$ bench-scale ESP operating on actual flue gas.

3. Obtain the data required for scaling up the technology by testing the two or three most promising conditioning agents at the pilot scale.

The first two phases of this program have been completed. The purpose of this report is to provide details on the results of the bench-scale testing of the additives. These results must then be judged against the measures of success that were defined in the Management Plan prepared at the beginning of the program. The following sections provide the brief summary of the results of the first phase of testing which were presented in the first topical report. This is followed by a description of the measures of success from the Management Plan.

\section{Summary of Previous Results}

\section{Selection of Additives}

The first technical task was to identify additives that could be injected into the flue gas to serve as an adhesive or wetting agent which would bind the fine particles together and thereby improve their collection in the ESP. In order to provide a more thorough coverage of potential conditioning agents, the search included products that were not specifically designed for ESPs. The major requirements of low toxicity and temperature stability were specifically noted. These products were reviewed to determine which ones are likely to survive and function in a flue gas at $300^{\circ} \mathrm{F}$. Table II-1 shows the additives that were selected for testing.

\section{Experimental Apparatus}

A laboratory flue gas simulator and injection chamber was used to produce a conditioned flue gas sample for evaluation in the ADA Field Resistivity Apparatus. The system, shown schematically in Figure II-1, was designed to provide a 1 to 3 acfm flow of gas 
with the following constituents: $0-40 \mathrm{ppm} \mathrm{SO}_{3} ; 0-4000 \mathrm{ppm} \mathrm{SO}_{2} ; 0-500 \mathrm{ppm} \mathrm{NO} ; 0-20 \% \mathrm{O}_{2}$; $0-12 \% \mathrm{H}_{2} \mathrm{O} ; 0-15 \% \mathrm{CO}_{2} ; 0-85 \% \mathrm{~N}_{2}$; and a particle loading of 0.5 to $8 \mathrm{gr} / \mathrm{acf}$.

Table II-1. Additives Tested During Initial Laboratory Screening

\begin{tabular}{|c|c|c|}
\hline Starches: & $\begin{array}{l}\text { Waxy corn starch (amylopectin) } \\
\text { Corn syrup }\end{array}$ & $\begin{array}{l}\text { Corn starch } \\
\text { Dextrin adhesives }\end{array}$ \\
\hline Gums: & $\begin{array}{l}\text { Gum arabic } \\
\text { Guar gum } \\
\text { Carrageenan } \\
\text { Agar }\end{array}$ & $\begin{array}{l}\text { Locust bean gum } \\
\text { Modified guar gum } \\
\text { Alginic acid } \\
\text { Xanthan gum }\end{array}$ \\
\hline Polymers: & $\begin{array}{l}\text { Poly(ethylene glycol) A } \\
\text { Poly(ethylene glycol) C } \\
\text { Polyvinylpyrrolidone }\end{array}$ & $\begin{array}{l}\text { Poly(ethylene glycol) B } \\
\text { Polyether polyol A }\end{array}$ \\
\hline Cellulose Derivatives: & $\begin{array}{l}\text { Methylcellulose } \\
\text { Sodium carboxymethylcellulose } \\
\text { Hydroxypropyl methylcellulose }\end{array}$ & \\
\hline Oils: & $\begin{array}{l}\text { Soybean oil } \\
\text { Mineral oil }\end{array}$ & Castor oil \\
\hline Waxes: & Paraffin wax & \\
\hline Polyacrylamide: & \multicolumn{2}{|l|}{ Acrylamide/bis-acrylamide A and B } \\
\hline
\end{tabular}




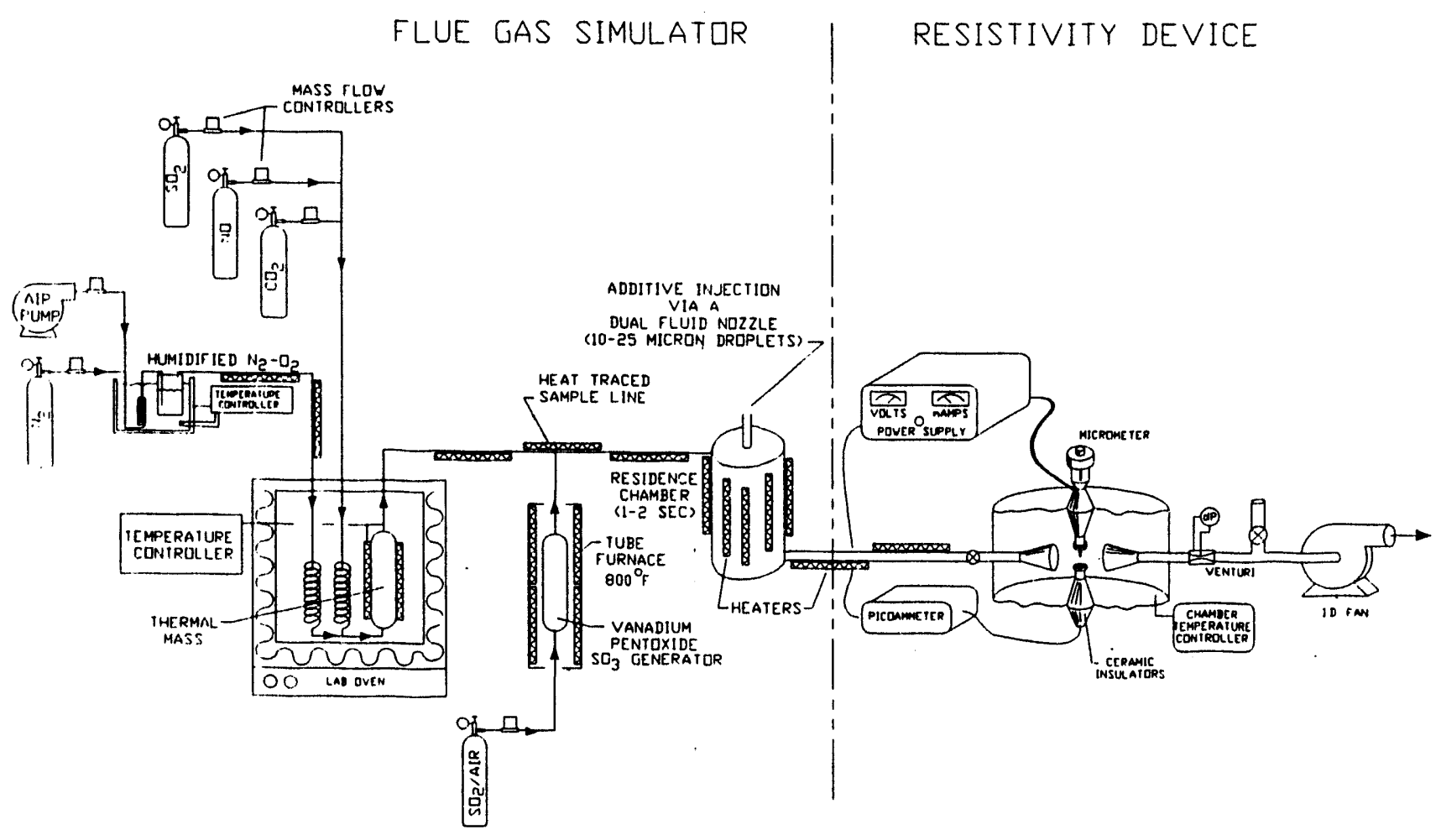

Figure II-1. Laboratory test apparatus for screening additives.

The dry gas phase constituents $\left(\mathrm{NO}, \mathrm{SO}_{2}\right.$, and $\mathrm{CO}_{2}$ ) are mixed and regulated using mass flow controllers and introduced into the heater/oven assembly. This dry gas mixture is then passed through a temperature controlled water bath/bubbler to produce the necessary $\mathrm{H}_{2} \mathrm{O}$ concentration. The bath/bubbler system was fully integrated in the flue gas simulation system 
with automatic controls. The humidified $\mathrm{N}_{2}-\mathrm{O}_{2}$ mixture is conveyed through heated sample lines to the heater/oven assembly where it is then mixed with the other gas constituents.

Sulfur trioxide is produced by passing sulfur dioxide and air through a vanadium pentoxide $\left(\mathrm{V}_{2} \mathrm{O}_{5}\right)$ catalyst bed maintained at $800^{\circ} \mathrm{F}$. A mini-dust feeder meters the fly ash into the system. The unit is equipped with a DC motor drive so that the feed rate can be adjusted, and the feeder has been calibrated for fly ash feed rates of 0 to 20 grains per minute. Fly ash samples collected from the pilot ESP at Consolidation Coal Company (CONSOL) while burning a Western Kentucky $3 \%$ sulfur coal were used as a standard for all of the screening tests.

The additive injection chamber was designed for a minimum residence time of two seconds for flowing flue gas. The chamber is four inches in diameter and sixteen inches long. The bulk of the simulated flue gas stream enters the chamber tangentially. A slipstream of the flue gas is taken upstream of the fly ash feeder. This "clean" gas is introduced tangentially to an additive carrier stream flowing into the conditioning chamber from below. The positions of the two flue gas inlets produced a countercurrent swirl for effective mixing in the conditioning chamber. A two fluid nozzle is used to spray the additives into the chamber. The conditioned flue gas exiting the chamber flows to a bench-scale resistivity precipitation chamber where dust is precipitated onto the lower grounded disc. This unit provides a means to measure the precipitation characteristics of the dust in simulated flue gas.

\section{Laboratory Screening of Additives}

For each additive, the tests were conducted by first operating at baseline conditions with no additives and then repeating the test with additives. In order to produce the identical gas stream characteristics under both baseline and additive conditions, the injection nozzle was operated for both cases. During baseline testing with no additive injection, a $0.5 \mathrm{cc} / \mathrm{min}$ feed of clean water is injected through the nozzle into the chamber. A $250 \mathrm{ml}$ flask acts as the liquid reservoir to the peristaltic pump. To start an additives injection test a $250 \mathrm{ml}$ flask containing an additive concentration is exchanged on the fly with the baseline water flask. At the completion of an additives injection test the process is reversed and a second baseline measurement can be performed. Tests are run for a constant duration. The data collected during each test includes the resistivity of the material, the thickness of the collected dust layer, photographic documentation of the precipitated dust and subjective indications of the dust characteristics. 
Figure II-2 shows a comparison of the performance of the most promising additives. The dark part of the boxes represents the thickness of the undisturbed precipitated layer, and the white part of the box represented the compacted thickness. The data are normalized so that the rate measured under baseline conditions represents unity. As can be seen, there were significant increases in the precipitation rate when the additives were injected.

The additives shown in Figure II-2 were injected at a rate to produce a concentration of approximately $0.1 \%$ of the mass of the fly ash in the flue gas. During the tests the gas stream characteristics, flow rate, particle resistivity, and ESP electrical conditions, were not affected by the addition of the additives. Therefore, it was concluded that the improved performance was due to increased cohesion. Because the precipitation disc is only a very small area compared to the volume of flow, even a minute increase in precipitation rate at this scale should result in a significant increase in efficiency in a full-scale ESP. However, with up to a five fold increase in precipitation rate in these tests, it is estimated that these additives have the potential to produce very large reductions in penetration.

The conclusion of increased cohesion is supported by changes in the physical characteristics of the ash. Figure II-3 shows photographs of the point-plane precipitator after a baseline test (fly ash only and no additives) and after a test of the same duration and fly ash feed rate with an additive injected. The additive increased the thickness of the precipitated layer, which appears to be more "fluffy". In addition, there is a significant increase in the amount of material deposited onto the upper electrode. This indicates that the resulting fly ash is indeed stickier.

The most successful candidates are non-toxic, as they are used in foods and cosmetic products. In addition, the chemicals are relative inexpensive. A very preliminary economic analysis indicates that the annual cost for additives for a $100 \mathrm{MW}$ plant would be in the range of $\$ 10,000$ to $\$ 100,000$. Since the additives will be capable of producing large reductions in emissions, these costs are significantly less that the costs associated with increasing the size of an ESP or adding a baghouise. 


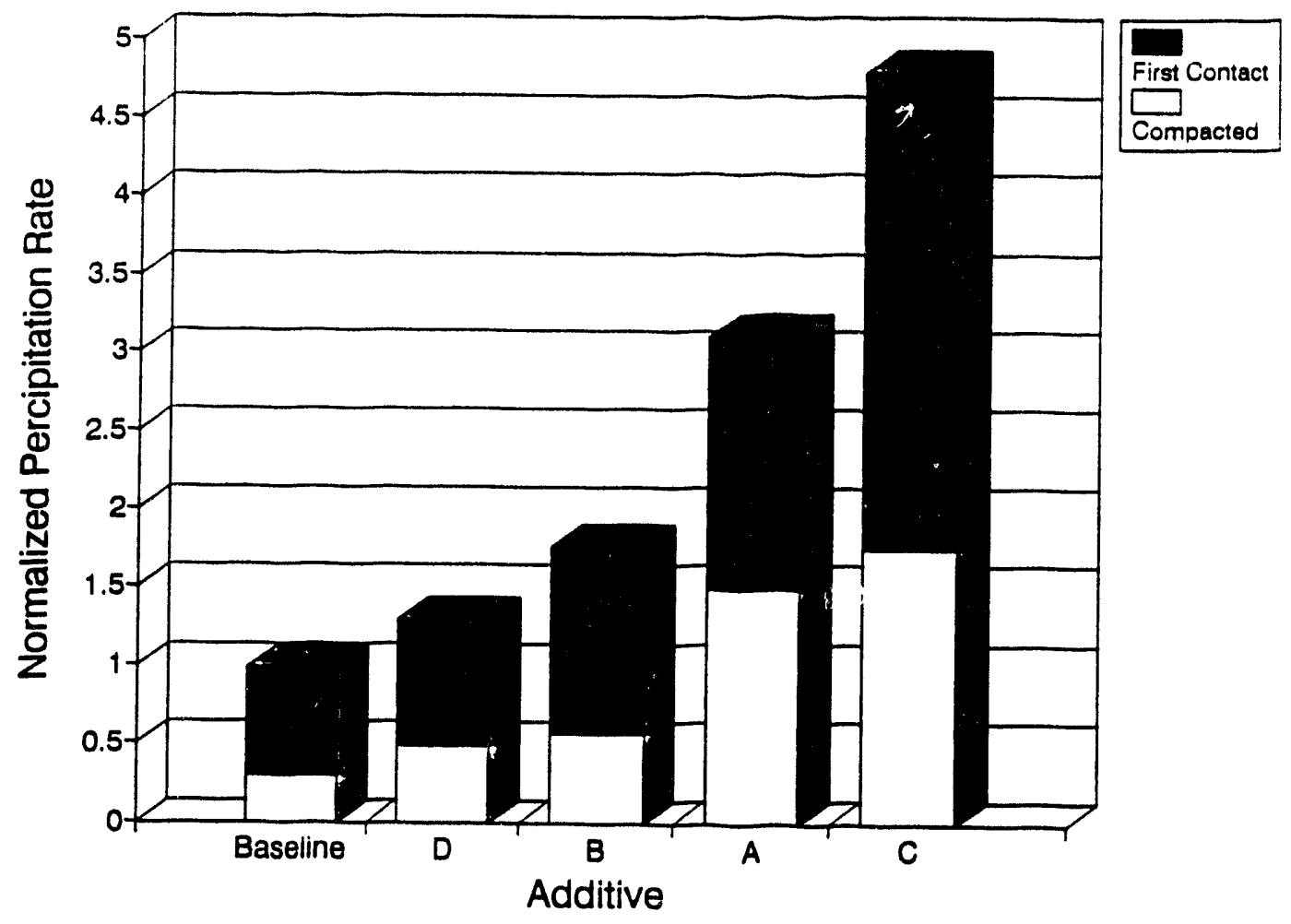

Figure II-2. Comparison of the precipitation rates for baseline conditions and with additives.
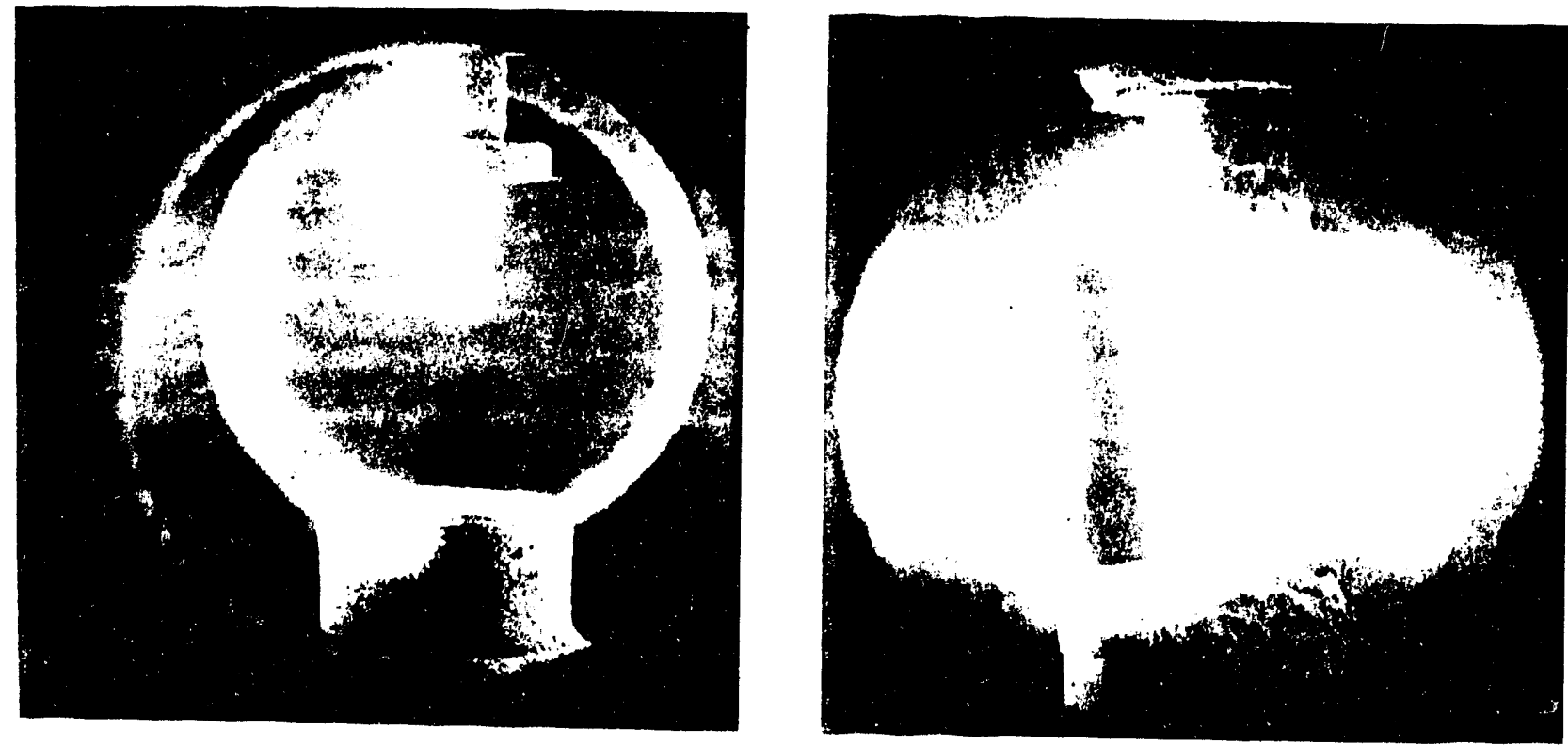

a. Baseline

b. With Additives

Figure II-3. Effect of additives on the characteristics of the precipitated dust. 


\section{Measures of Success}

This program has two key decision points. The first occurs at the end of the benchscale tests. After the data is analyzed, it will be necessary to rate the performance of the additives and to determine whether the improvements produced by the additives : $:$ arrant additional testing at the pilot-scale. A similar decision will have to be made at the end of the pilot-scale tests. The experimental data obtained during Task 5 will be viewed in conjunction with the waste characterization, ESP modeling, and economic analysis to determine if the results show sufficient promise that DOE would consider additional funding to demonstrate the technology at a full-scale installation.

Although, these decisions might initially appear to be straight forward, a closer look at the technical issues involved reveals that it will be difficult to establish objective quantitative goals for the program that can be expressed in terms of a measurable improvement in performance.

The nature of the difficulty in establishing measures of success lies in the problem being addressed in this program. The objective of the program is to investigate conditioning agents that will produce improved collection efficiency of fine particles in an electrostatic precipitator. However, the additives will not have any impact on the primary particle collection mechanisms which are well understood theoretically and are easy to experimentally verify. Instead, the additives will produce their desired effect by modifying only the non-ideal effects, and these are not associated with either solid fundamental understanding or specific measurement technologies.

The "non-ideal effects" represent, by definition, the mechanisms that cannot be explained by ESP theory but are a very real part of the performance of a full-scale ESP. The non-ideal effects fit into several categories which include:

- Sneakage

- Maldistribution of gas flow

- Non-rapping reentrainment

- Rapping reentrainment

- Hopper reentrainment

Since the first two non-ideal effects are due to the gas flow characteristics which result from the physical configuration of the ESP, the additives cannot be expected to affect these 
processes. However, an additive that increases the cohesive characteristics of the particles could decrease the magnitude of all forms of reentrainment.

The magnitude of rapping reentrainment can be measured by comparing emissions with and without rapping. However, the other non-ideal effects are continuous processes and are therefore difficult to quantitatively characterize. By measuring emissions at the outlet of an ESP, it is not possible to determine whether the particles are penetrating the ESP because they have not been collected or because they have either been reentrained or have by-passed the active sections of the ESP. About the only possible means to determine the cause of emissions, is to compare actual performance with theoretical performance and then attribute the difference to non-ideal effects. However, this technique can only be effective if the nonideal effects result in a significant contribution to the total emissions.

The role that the non-ideal effects play in ESP performance vary from unit to unit, but in general, the greater the collection efficiency, the greater the impact of the non-ideal effects. For a high efficiency ESP (i.e. $99.9 \%$ collection efficiency), non-ideal effects can be the root cause of the majority of emissions. Therefore, a process that reduces reentrainment will result in a large reduction in emissions. However, for a smaller and subsequently less efficient ESP, a similar reduction in the magnitude of reentrainment will have a lesser impact on overall emissions. For these reasons, any definition of a measure of success will have to take into consideration the size and performance of the ESP.

Another difficulty in defining a measure of success results from interpreting data obtained from reduced-scale precipitators. Although the additives have the potential for reducing all forms of reentrainment, rapping reentrainment and hopper boil-up cannot be adequately simulated in the bench-scale ESP. The primary effect of the additives that will be characterized in these tests will be non-rapping reentrainment. In the pilot-scale tests, rapping and hopper reentrainment will begin to become a factor, but because the plate height in the pilot unit is much smaller than full-scale plates; the magnitude of the effects of these forms of reentrainment will not be as significant. Therefore, a small improvement produced in the bench-scale and pilot-scale tests should represent the potential for a much greater amount of improvement when the additive is used in a full-scale unit.

Another major uncertainty is due to the fact that the ultimate target for this technology is not adequately defined at this point in time. The additives will be used as a retrofit technology on existing ESPs. The need for improving the performance of an existing ESP. will be driven by either local regulations requiring a decrease in emissions or new regulations 
related to air toxics imposed at the national level. Since these specific standards will not be established until some time in the next couple of years, assumptions will have to be made about the specific targets for this program.

The final uncertainty is due to the site specific nature of the benefits of this technology. The relative reduction in outlet emissions produced by the additives increases with ESP efficiency. However, the lower the baseline efficiency, the greater the improvements have to be to meet a fixed standard. Therefore, there will be an optimum size ESP for this technology which will depend on the new regulations. If an ESP is very small, there may not be sufficient improvement available with the additives to reach the emission limits. On the other hand, very large ESPs may not need any improvement at all.

The age of the boiler might also play an important role in determining the costeffectiveness of the additives. If there are many years of life lett on a boiler, there might be justification of a large capital expenditure for a baghouse or new ESP. However, for a very old boiler with only a fews years of service remaining, the low-capital costs associated with chemical conditioning might appear very attractive.

In conclusion, defining a measure of success must take into account all of the factors mentioned above. In order to do this it will be necessary to use the computer ESP model to extrapolate the data from the small-scale systems to the various full-scale units. This analysis must then be incorporated into the economic analysis to define the potential for success. Therefore, the measures of success must be expressed in terms of providing improved collection efficiency in a cost-effective manner.

\section{Measures of Success for Bench-Scale Tests}

The bench-scale tests are very important because they represent the first test site where the additives must function in the presence of actual flue gas. However, the small size of the test unit eliminates many of the means by which the additives could provide an improvement in performance. Therefore, a small improvement in performance in the bench-scale tests could lead to a much greater improvement when applied to a larger-scale unit. Therefore, success for an additive will be achieved if a statistically significant improvement in collection efficiency occurs. If many additives meet this criterion, then the additives will be rated according to the magnitude of improvement. 


\section{Bench-Scale Testing}

ADA conducted bench-scale (100 acfm) testing of additives at the Consolidation Coal Company Research and Development Laboratory in Library, PA. The purpose of the testing was to evaluate the performance of four additives for improving the particle collection ability of electrostatic precipitators (ESPs).

\section{Bench-Scale Apparatus}

Bench-scale testing was conducted from May 10 through May 21, 1993. Flue gas from the CONSOL pilot combustor duct was drawn through an isokinetic probe assembly, into an injection chamber where the conditioning agents were introduced, through ADA's bench-scale ESP, and then through a flow measuring venturi by the system's ID fan. The flue gas exiting the ID fan was returned to the combustor. Isolation valves were located at the isokinetic probe and downstream of the ID fan. A sketch of the arrangement is shown in Figure III-1.

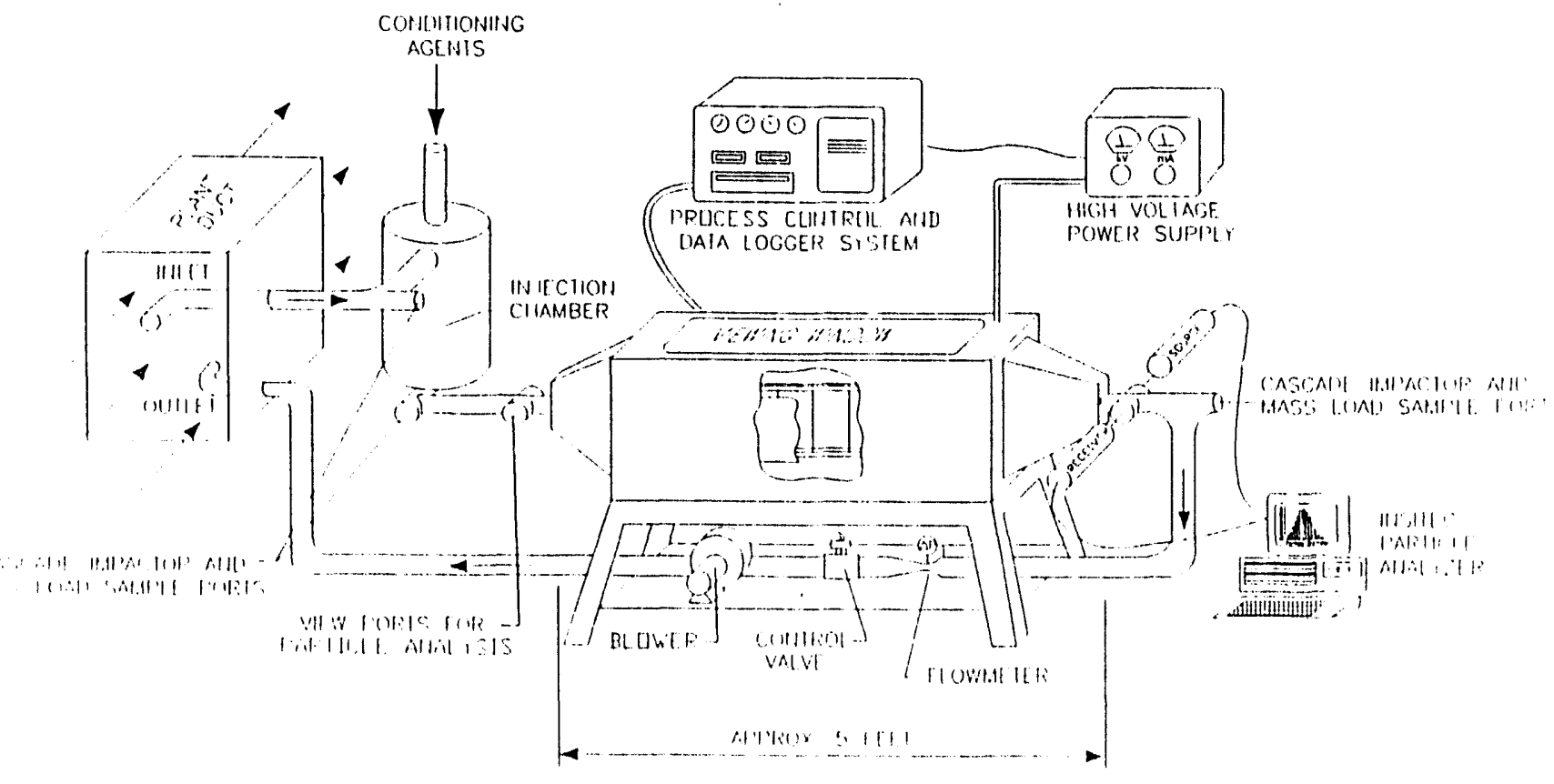

Figure III-1. Bench-scale ESP arrangement. 


\section{Residence Chamber and Additive Injection}

The residence chamber was sized to provide a nominal residence time of 2 seconds for $100 \mathrm{acfm}$ of flue gas. The chamber consisted of a 12 inch diameter, 4 foot high cylindrical vessel with co-current mixing of additive and flue gas. Flue gas entered the heated chamber tangentially near the top of the vessel and spiraled to the perpendicular exit located near the chamber's base. The additive was injected through a nozzle mounted tc the upper blind flange on the residence chamber.

The additive was metered to the injection nozzle using a peristaltic pump. The initial calibration indicated that the accuracy of the pump was within $\pm 1 \%$ for the desired additive flow rate range ( 3 to $10 \mathrm{cc} / \mathrm{min}$ ). The injection nozzle was a dual fluid nozzle which required air to produce the desired additive spray pattern. The air pressure was manually controlled and monitored with the other system flow and pressure parameters.

\section{Bench-Scale ESP}

The ADA portable bench-scale ESP was used at the CONSOL combustion research facility for on-site evaluation of the flue gas conditioning agents. The ESP is sized for a nominal $100 \mathrm{acfm}$ of flue-gas using 12 inch high, 36 inch long plares which can be installed at various plate-to-plate spacings. For this test, five plates were spaced 2.25 inches apart to form 4 gas passages and to provide an SCA of $240 \mathrm{ft}^{2} / \mathrm{Kacfm}$. The discharge electrodes are supported by a rigid frame. The electrodes are 0.1 " diameter wires spaced 4 inches apart. A drawing of the ESP as configured at CONSOL is shown in Figure III-2.

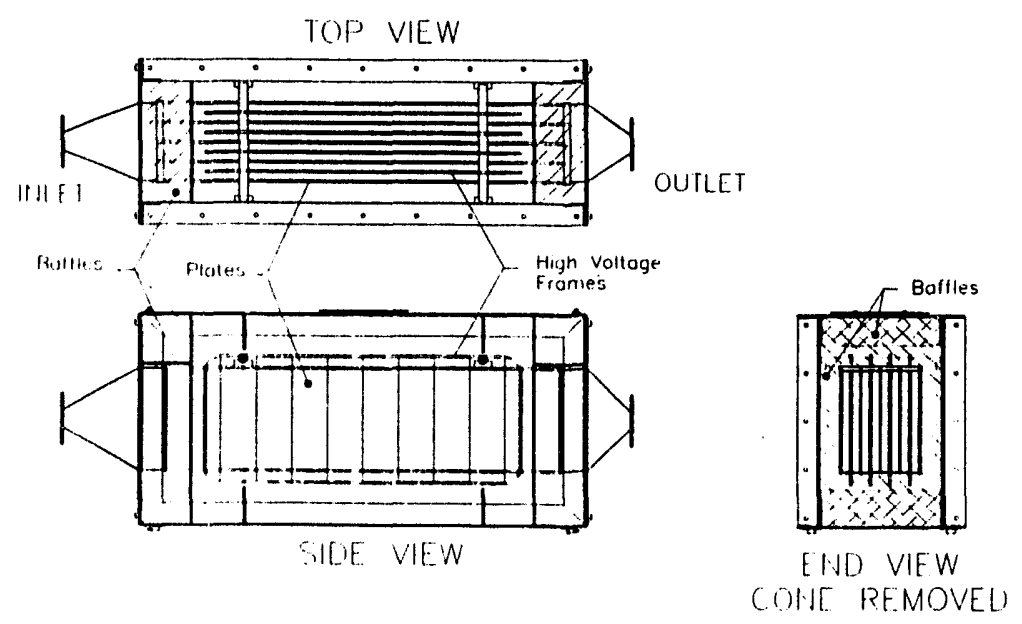

Figure III-2. Drawing of bench-scale ESP. 
Inlet and outlet cones were designed to provide an even distribution of flow across the ESP. The inlet cone used a diverging 30 degree angle to decelerate the flow from duct velocity to ESP velocity. The outlet cone used a 60 degree converging angle to accelerate the flow back to duct velocity. Flow distribution plates were also placed in the inlet and outlet cones to straighten the flow.

A high voltage power supply was sized to allow operation up to $25 \mathrm{Kv}$ and $5 \mathrm{~mA}$. At full capacity with the ESP arrangement at CONSOL, the power supply could potentially produce a field strength of $8.75 \mathrm{kV} / \mathrm{cm}$ and a current density of $224.3 \mathrm{nA} / \mathrm{cm}^{2}$.

The ESP was heated and insulated to control and maintain a constant operating temperature. The system can be operated from ambient to $400^{\circ} \mathrm{F}$. The temperature controllers were used in conjunction with the temperature controllers throughout the system to minimize hot or cold spots which might bias the results.

The original ADA ESP design did not include a rapping mechanism. The ESP was modified for these tests to manually rap the plates from outside the box. The plate hanger at the outlet end of the ESP was connected to a rod which extended through the top of the box. A ratchet mechanism was incorporated to lift the back end of the plates approximately $1 / 2$ inch and drop them back on their mounts.

\section{System Control}

The experimental arrangement was designed for a high level of control. An intelligent data logger acted as the temperature controller for the ESP box. The ESP box was divided into three temperature zones with 6 thermocouples in the first zone, 5 in the second, and 5 in the third. The data logger monitored the 16 skin temperatures and controlled the zone temperatures with a PID.

Three temperature controllers mounted in a portable case controlled the temperature of the residence chamber, the inlet duct to the ESP, and the ESP outlet duct. Additional thermocouples were mounted on the top of the residence chamber, the ESP inlet and outlet cones, and the flow measuring venturi to monitor system temperatures.

Magnehelic gauges were mounted in a portable case to monitor system pressures including static pressures in the additives chamber and the ESP inlet and outlet, the injection nozzle air pressure, and the pressure drop across the flow measuring venturi. Manual flow' 
controllers in the case were used to monitor and control the injection nozzle air flow and the Insitec viewport window purge air flow. The system flow, as monitored by the flow measurement venturi, was controlled manually using a bypass valve at the ID fan.

The power supply was controlled manually and was not capable of proportional control. When the ESP sparked, the power supply tripped and was reset manually by the ADA engineer operating the system.

\section{Particle Measurement}

To provide real-time feedback on the effects of the additives on ESP performance, ADA acquired a laser particle size and velocity measurement system: the Insitec Particle Concentration, Size, and Velocity instrument, model E (PCSV-E). The hardware consists of a U-shaped bridge unit that houses the optics for a laser transmitter and receiver, a signal processing unit, and an advanced personal computer that performs the computations and displays measurement results.

The optical window at the inlet of the ESP was located more than eight duct diameters upstream of the ESP inlet cone. Another Insitec window was located at least eight duct diameters downstream of the ESP outlet. Purge rings were installed on each window. These rings kept the optical windows clean by allowing a flow of compressed air to flow across the interior surfaces of the windows.

The Insitec PCSV-E laser particle sizing instrument was used in conjunction with the more conventional modified EPA Method 17 manual sampling procedure to compare the total particulate loading measured by each method. Method 17 ports were located upstream of the inlet Insitec window and downstream of the outlet Insitec window. The flue gas sample was drawn through a straight tube nozzle attached to a $47 \mathrm{~mm}$ Gelman filter where the ash sample was collected. The filter was maintained at or above duct temperature with a heating mantle.

\section{Test Site Description}

Bench-scale ESP experiments were conducted at the CONSOL 1.5-million BTU/hr combustor facility. The unit is designed to simulate the combustion environment of a utility boiler. Blaskville \#2, a $1.9 \%$ sulfur bituminous coal from a Pittsburgh seam, was burned during the tests. 
CONSOL allowed ADA to have access to one of their test ports during a two week test burn. The availability of the test port to ADA was coordinated by CONSOL to accommodate the test schedules of both companies. During the ADA tests, the combustor was brought on line with natural gas. Stable operation at temperature was attained Tuesday during the day. The combustor was brought down on Friday. During stable operation, the ADA ESP inlet scoop was removed from the duct for five hours each day to facilitate CONSOL's use of the test port. During this time, ADA equipment was moved to allow access to the test port and ADA personnel were asked to leave the area due to the limited space. Tear down, set-up and warm-up each day reduced the projected 24 hour testing day to nominally 14 hours. Total testing time for the two week test period was approximately 80 hours.

\section{On-Site Testing}

ADA personnel arrived on site May 5, 1993. During the remainder of the week, the test equipment was installed and thoroughly inspected by CONSOL's safety team. All equipment components were checked out and debugged during the week. The Insitec particle analyzer was found to operate marginally, therefore arrangements were made for a consultation call to the test site by an Insitec representative the following week.

CONSOL began to bring the combustor on-line the week of May 10, 1993. While the CONSOL system was warming up, the Insitec analyzer was calibrated and the Insitec control software was modified by an Insitec representative for optimal operation. The laser was aligned at the inlet and outlet ports to provide maximum power.

The bench-scale ESP was "lined-out" on May 11 to operate at $10-12 \mathrm{kV}$ at a current of 0.5-1.5 mA. These correspond to a field strength of $4.4 \mathrm{kV} / \mathrm{cm}$ and a current density of 22.4 $\mathrm{nA} / \mathrm{cm}^{2}$. Consistent operations (i.e., no trip conditions due to excessive sparking or tracking) were achieved at these setpoints.

Results from Task 4.1, Comparison of Insitec Instrument with Inpactors, indicated the Insitec instrument is very useful for providing real time data on both the mass and particle size distribution for particles less than 10 microns. One of the two ADA engineers on site operated the Insitec while the other maintained the system operating parameters and conducted Method 17 mass tests. Several Insitec runs were conducted at each test condition determine temporal trends and to establish a representative particle size distribution and total mass value. 
Tests were run using additive " $\mathrm{C}$ " during this period of time at different concentrations. These runs were short-duration screening tests of 1-to 2-hours each. Concentrations of approximately $0.005 \%, 0.05 \%, 0.5 \%$, and $2.5 \%$ (wt. additive : wt. ash) were injected into the flue gas. Following the screening tests, an injection rate of $0.05 \%$ was chosen for all further tests based on initial results and economic considerations. Additives "A", "B" and "D" were also tested throughout the week.

A primary factor which can limit the performance of an ESP is sneakage. Sneakage occurs when a portion of the particle laden gas by-passes the active regions of the ESP. During the second week of testing, additional baffles were installed into the ESP to reduce the potential sneakage. Figure III-3 is a sketch of the potential sneakage path after the additional baffles were installed. The sketch shows the baffles at the inlet and outlet to better direct flow through the active section of the ESP. There is a high proportion of dead-space in the ADA ESP as compared to full-scale ESPs because of the bench-scale's relatively small plate area as compared to the wire-to-plate spacing, and because the unit was designed for variable plate spacing. At the wider plate spacings, an adequate distance must be maintained between the high voltage frames and the box to prevent sparkover. After the additional baffles were installed, the sneakage appeared to be nominally $15 \%$. The modification improved the efficiency of the ESP from approximately $50 \%$ to over $70 \%$.

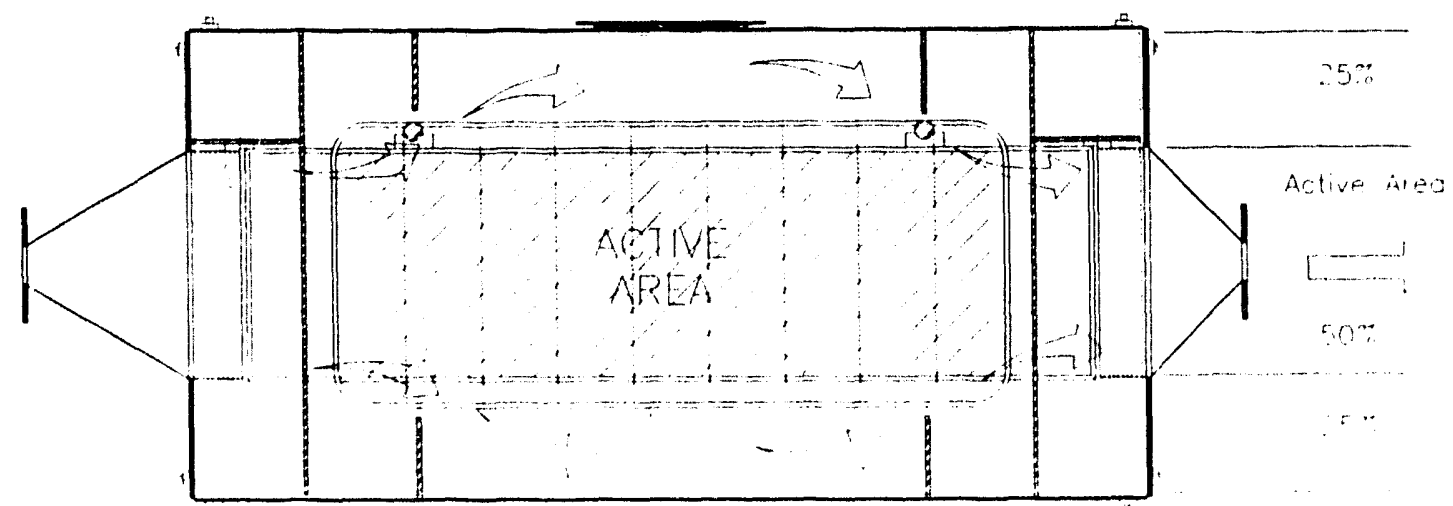

Figure III-3. Potential sneakage path. 
The increase in efficiency also lead to a more rapid build-up of fly ash on the ESP collection plates. Recall that the plate-to-plate spacing for this test was 2.25 inches. At this plate spacing, ash build-up on the plates rapidly increases the effective field strength of the ESP. For example, with $1 / 8$ " of ash on the plates, the effective plate-to-plate distance is reduced to 2 inches. This causes a $12.5 \%$ increase in the field strength. As more ash collects, the field strength increases further until the ESP sparks. During the second week of testing, the ESP was thoroughly "rapped" every 15 to 20 minutes. A thorough rapping consisted of opening the box and scraping down the plates to ensure that the baseline field strength was recovered.

In an effort to increase the operating current density, the first wire electrodes in each gas passage was removed and replaced with a barbed electrode. The electrical characteristics for the two configurations are shown in Figure III-4. It became readily apparent that the increased current density at the first wire caused the ash to quickly collect on the area of the plates adjacent to the wire. Ash build-up on the plates resulted in premature ESP sparking. The wire electrode was replaced and all further tests were conducted with this configuration.

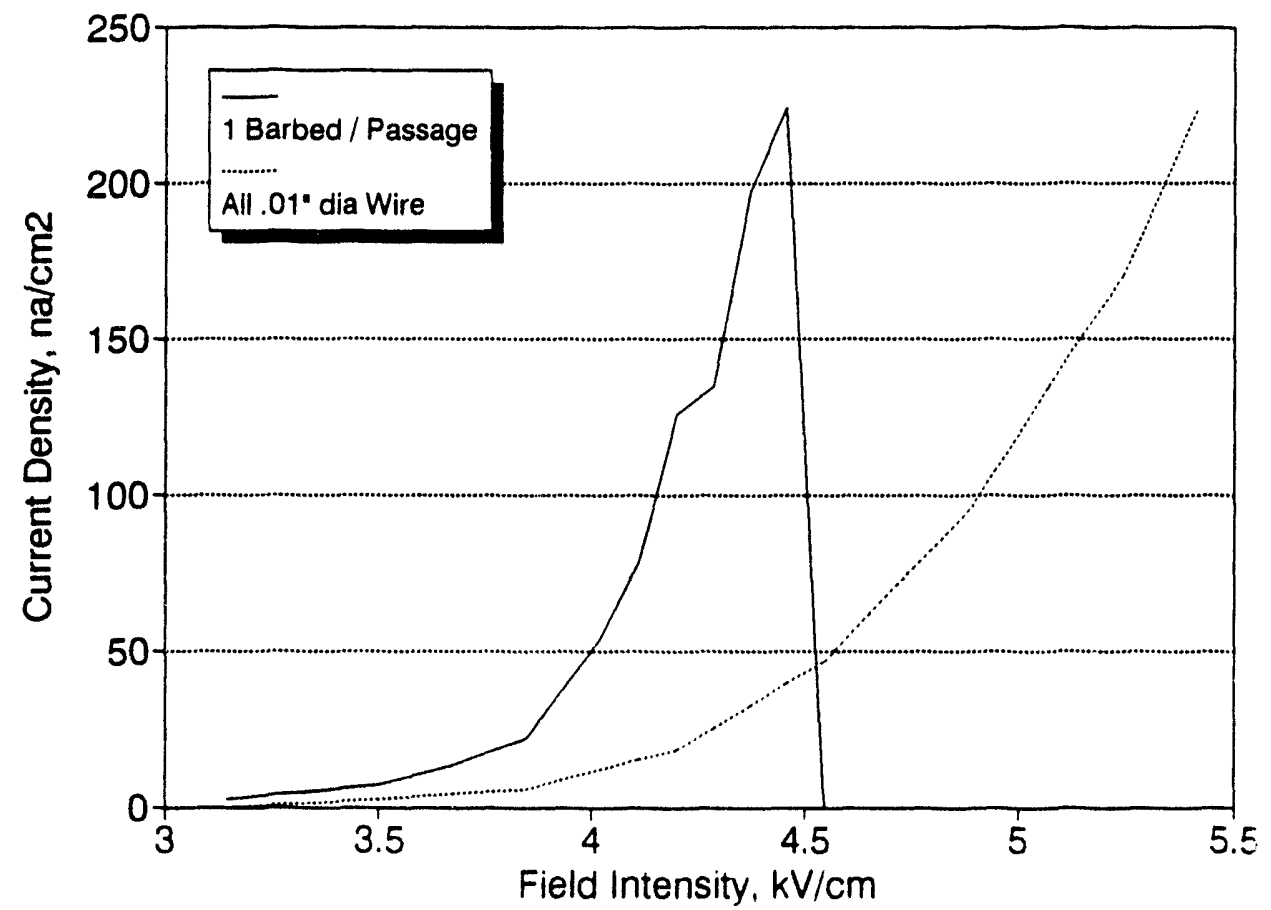

Figure III-4. Field Strength and current density comparison for two wire configurations. 


\section{Test Results}

\section{Subjective Observations}

Visual observations of runs during additive " $\mathrm{C}$ " and " $\mathrm{D}$ " injection showed that fly ash would dislodge in "flakes" when the collection plates were rapped. Particle buildup did not appear any more severe using the additive than under "no-additive" conditions. The ash layer also appeared to have more texture when additives were used.

\section{Evaluation of the Insitec Instrument}

Initial results indicated that the Insitec instrument measures much greater particle concentrations than the Method 17 samples at the inlet. This is due to a factor first reported by Holve, et al. (1988), where large fly ash particles appear to scatter laser light more like transparent particles than opaque particles. The result is that the Insitec deconvolution algorithm calculates the sizes of these more-efficient scattering particles as larger than their actual dimension. The impact is further aggravated by the fact that many of these large particles are unburned carbon or spherical shells rather than high-density fly ash material (Bonin and Queiroz, 1992). The particle fraction greater than 10 microns in diameter thus is reported as oversized by the Insitec. This fraction comprises a very large portion of the total mass loading at the inlet.

Therefore, the data were screened to provide information only on particles less than 10 micrometers in diameter. Particle loading samples were collected using EPA Method 17 to occasionally check the Insitec data trends. Figure IV-1 shows a comparison of the mass concentrations measured at the inlet and outlet by the Insitec instrument and by modified Method 17. The mass fraction less than 10 micrometers in diameter as measured by the Insitec are consistently about $20 \%$ less than the total mass determined by the modified Method 17 measurements. The use of Insitec data for tracking particles that are less than 10 micrometers in diameter is based on the following criteria: 1) the Insitec analyzer is being used for rapid data trend analysis, 2) it is the small particle fraction that is targeted for control in the program, and 3) there is a correlation between the Insitec data for small particles and the Method 17 data which measures all particles. 


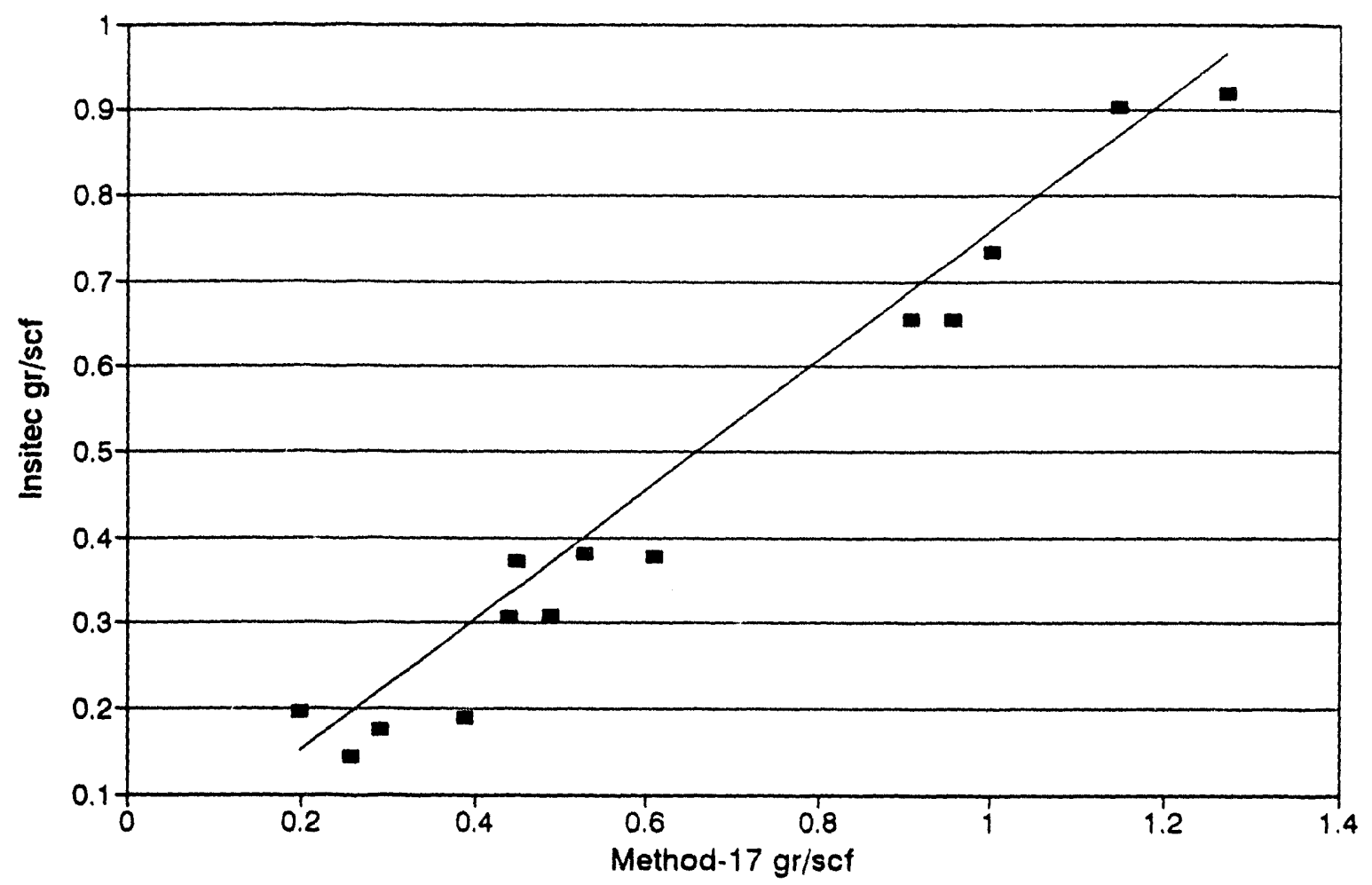

Figure IV-1. Comparison of Method 17 and Insitec.

\section{Flue Gas Conditioning with Additives}

During an initial 5 hour test, additive " $\mathrm{C}$ " was injected at rates varying from $0.005 \%$ to $2.5 \% \mathrm{wt}$. additive/wt. ash over a five hour period. A rate of $0.05 \%$ was chosen for the main testing based upon preliminary economic studies and positive results from the initial test. The short initial test did not provide enough data to confidently predict the effect of differing injection rates. Furthermore, due to time constraints, the injection rate was not optimized during the bench-scale testing. Injection rates for additives "A", "B", and "D" were chosen to be economically comparable to additive "C".

Table IV-1 shows a summary of the results of the additives tests during both weeks of testing. Additive "A" was injected at $0.05 \%$ (wt. of additive to wt. of fly ash) and was found to pose operational problems for the ESP almost immediately. The ESP began sparking and 
outlet particle loadings increased from baseline levels by an average of $8 \%$. Additive "B" was injected at a concentration of $0.02 \%$ and was found to slightly decrease the outlet particle loading by $2 \%$ as compared to the baseline conditions. Additive " $\mathrm{C}$ " was injected at a concentration of $0.05 \%$. Results show that the additive improved collection efficiency from $40 \%$ to $50 \%$ during the first week of testing, and from $65 \%$ to $74 \%$ during the second week after additional baffles were installed in the ESP. This represents a reduction in emissions of $17 \%$ and $27 \%$. Additive "D" was injected at a concentration of $0.05 \%$ and was also found to be effective by reducing outlet mass loadings $17 \%$ as compared to baseline (no additive) conditions.

Table IV-1. Summary of Results

\begin{tabular}{|cccccc|}
\hline $\begin{array}{c}\text { Test } \\
\text { Date }\end{array}$ & $\begin{array}{c}\text { Test } \\
\text { Condition }\end{array}$ & $\begin{array}{c}\text { Collection } \\
\text { Efficiency }\end{array}$ & $\begin{array}{c}\text { Particle } \\
\text { Penetration }\end{array}$ & $\begin{array}{c}\text { Emission } \\
\text { Reduction }\end{array}$ & $\begin{array}{c}\text { Test } \\
\text { Temperature }\end{array}$ \\
\hline $5 / 13$ & Baseline & $40.4 \%$ & $59.6 \%$ & & $307^{\circ} \mathrm{F}$ \\
$5 / 13$ & Additive C & $50.4 \%$ & $49.6 \%$ & $16.8 \%$ & $308^{\circ} \mathrm{F}$ \\
$5 / 14$ & Baseline & $34.4 \%$ & $65.5 \%$ & & $305^{\circ} \mathrm{F}$ \\
$5 / 14$ & Additive A & $28.9 \%$ & $71.1 \%$ & $-8.5 \%$ & $307^{\circ} \mathrm{F}$ \\
$5 / 14$ & Baseline & $42.8 \%$ & $57.2 \%$ & & $300^{\circ} \mathrm{F}$ \\
$5 / 14$ & Additive B & $44.1 \%$ & $55.9 \%$ & $2.3 \%$ & $305^{\circ} \mathrm{F}$ \\
$5 / 14$ & Additive D & $52.4 \%$ & $47.6 \%$ & $16.8 \%$ & $287^{\circ} \mathrm{F}$ \\
\hdashline $5 / 19 *$ & Baseline & $64.6 \%$ & $35.4 \%$ & & $308^{\circ} \mathrm{F}$ \\
$5 / 19 *$ & Additive C & $74.3 \%$ & $25.7 \%$ & $27.4 \%$ & $307^{\circ} \mathrm{F}$ \\
\hline
\end{tabular}

* Baffles were added to the ESP during the second week of testing to reduce sneakage.

Figure IV-2 shows a comparison of the average particle size distributions for baseline outlet conditions and outlets while additive " $\mathrm{C}$ " was injected at $0.05 \%$. As is shown, the additive causes a significant and fairly uniform decrease in emissions for particles below 10 micrometers in diameter, the range of accuracy for the Insitec.

\section{References}

Holve, D.J., P.L. Meyer, L.J. Muzio, and G.H. Shiomoto, (1988). "On-Line, In-Situ Particle Measurements in a Large Scale Coal-Fired Furnace". Paper \#88-60, Western States Section of the Combustion Institute, Salt Lake City, UT, March. 


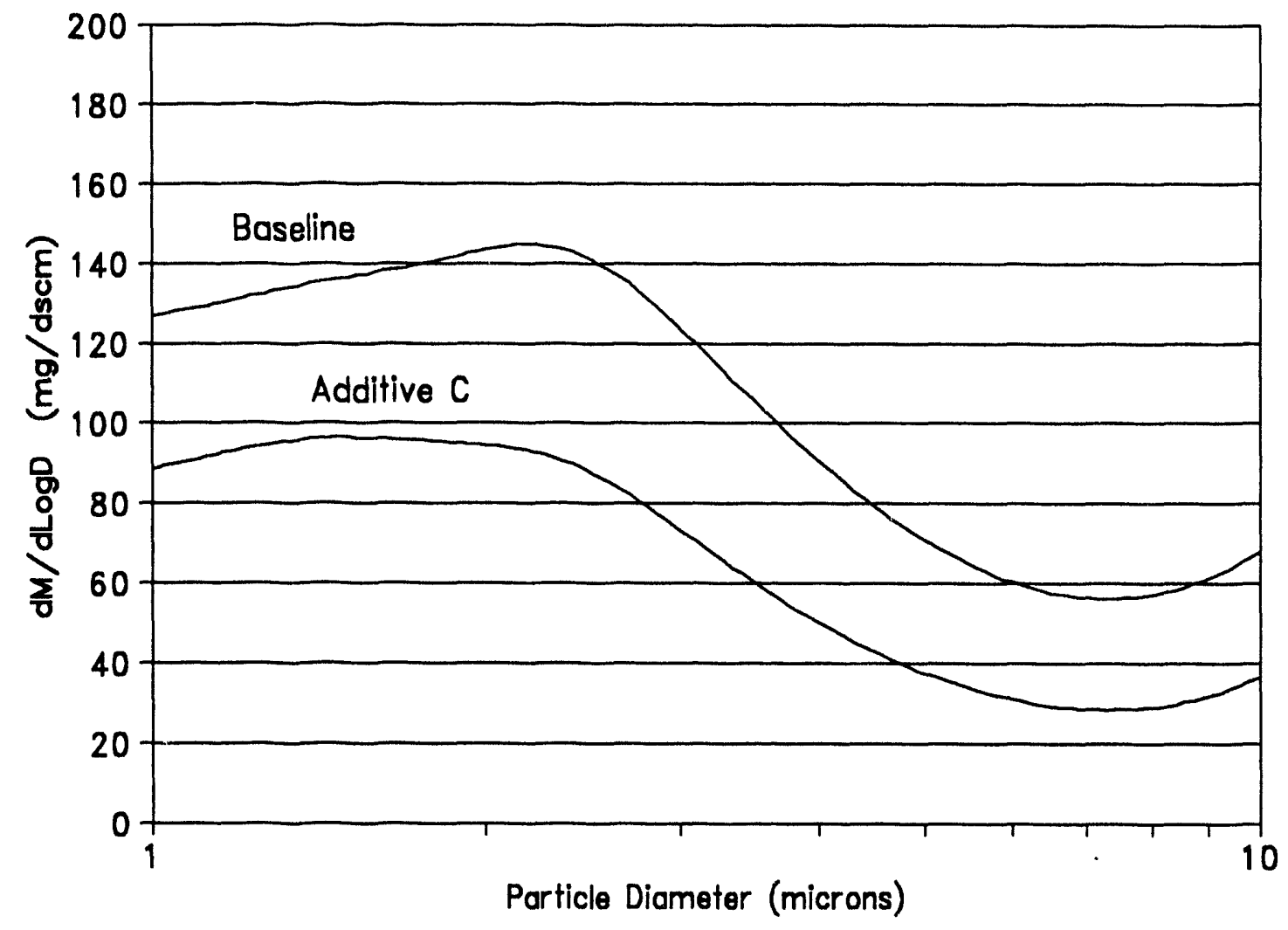

Figure IV-2. Particle size distribution for baseline conditions and additive C. 


\section{Analysis}

\section{Scanning Electron Microscopy Examination}

Samples of fly ash were examined using scanning electron microscopy by the Mountain Technical Center (MTC). MTC is a unit of Schuller International, formerly known as Manville Corporation. The following samples were examined:

- $\quad$ Bench-scale ESP catch during additive " $\mathrm{C}$ " addition.

- Bench-scale ESP catch during additive " $D$ " addition.

- CONSOL baghouse catch. This sample was for control purposes. CONSOL used a baghouse to collect the fly ash from the combustor during the 2-week test. This ash was not exposed to additives, therefore a sample was collected for examination as a baseline case.

Figures V-1 through V-3 show photomicrographs of the fly ash samples. All samples showed spherical particles ranging in diameter from 0.5 to 50 micrometers accompanied by small amounts of angular debris. The baghouse samples generally showed a broader range of particle sizes than the ESP/additive samples. Particles tend to pack tighter with a broad size distribution. Inspection of the baghouse catch sample showed some agglomeration, most likely due to size distribution packing effects and due to impaction effects as the particles were collected on bag surfaces. The ESP/additive samples showed agglomerates which were smaller and more homogeneous clusters. The clusters were typically equidimensional, 10 micrometers in diameter, and composed of particles of similar size. The result of agglomerating finer particles into larger masses is believed to improve ESP collection efficiency and reduce reentrainment losses. Microscopy results can occasionally be subjective, and subtle differences in appearance may indicate a dominating macroscopic effect. The results seem to indicate that smaller particles are combining to form larger clusters in the $\mathrm{ESP} /$ additive cases, verifying the measured improvements in ESP collection efficiency. 

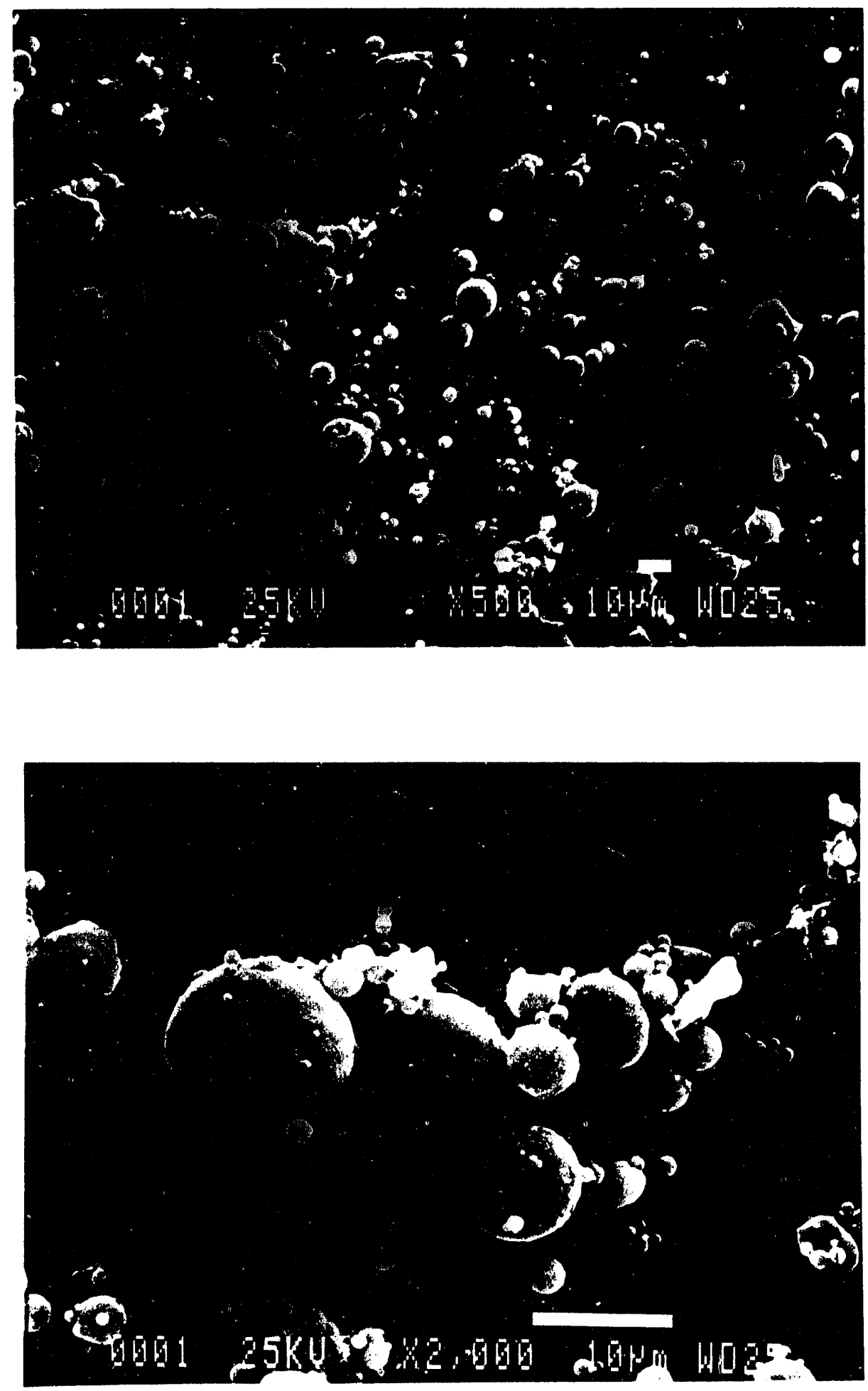

Figure V-1. Photomicrographs of CONSOL baghouse catch fly ash sample. Magnification of top photo is $500 \mathrm{x}$, and magnification of bottom photo is $2,000 \mathrm{x}$. 

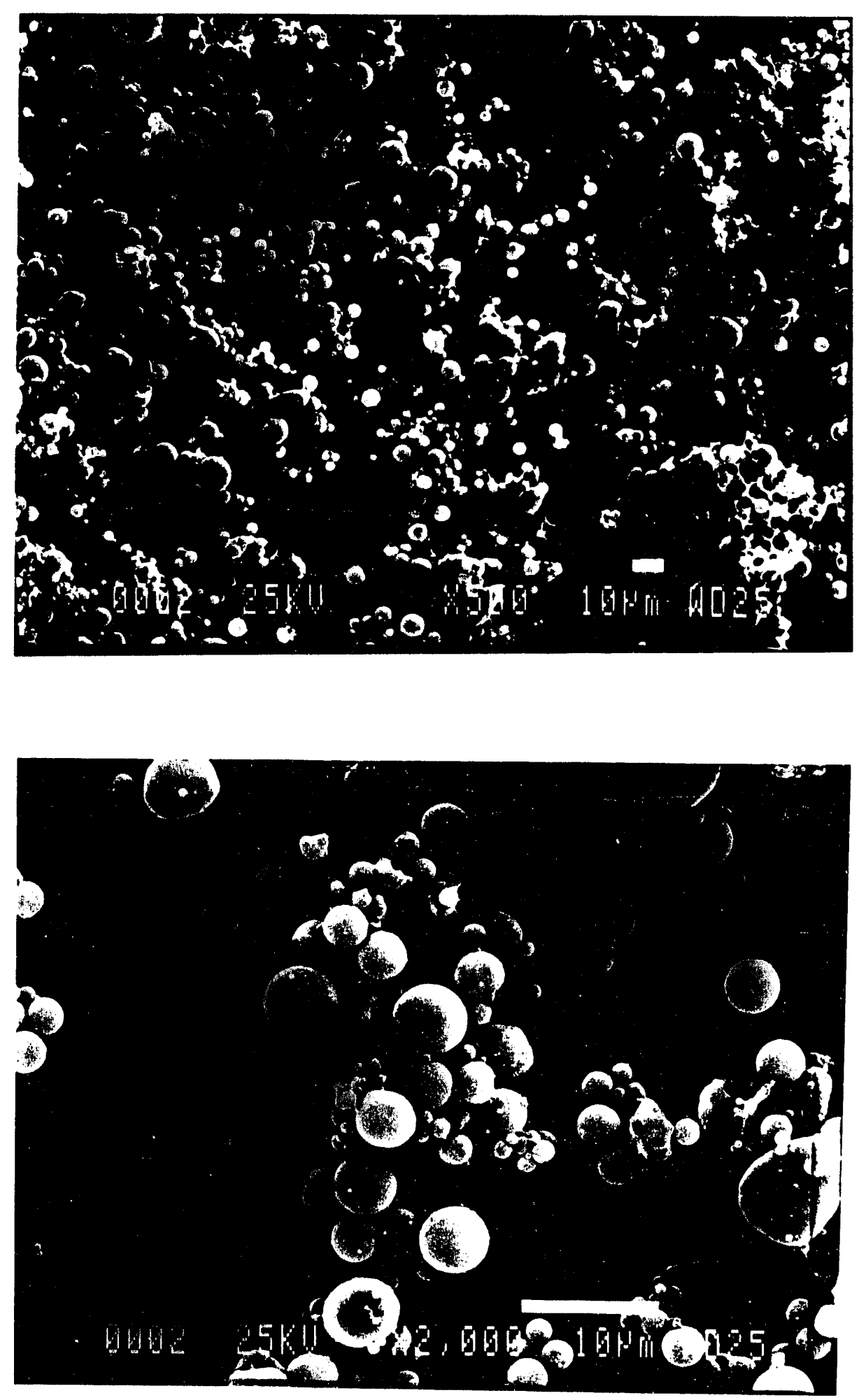

Figure V-2. Photomicrographs of ESP/Additive "C" fly ash sample. Magnification of top photo is $500 \mathrm{x}$, and magnification of bottom photo is $2,000 \mathrm{x}$. 


\section{Elemental Analysis of Ash}

A sample of ash was analyzed for elemental constituents by Hazen Research, Inc. of Golden, CO. The ash sample was collected from the CONSOL baghouse collecting the fly ash from the research combustor. The analysis is given in Table V-1.

Table V-1. Elemental Analysis of Ash

\begin{tabular}{|cc||}
\hline Compound & wt. \% \\
\hline $\mathrm{SiO}_{2}$ & 43.04 \\
$\mathrm{Al}_{2} \mathrm{O}_{3}$ & 22.66 \\
$\mathrm{TiO}_{2}$ & 0.86 \\
$\mathrm{Fe}_{2} \mathrm{O}_{3}$ & 7.95 \\
$\mathrm{CaO}$ & 5.90 \\
$\mathrm{MgO}$ & 0.80 \\
$\mathrm{Na} O$ & 0.83 \\
$\mathrm{~K}_{2} \mathrm{O}$ & 1.72 \\
$\mathrm{P}_{2} \mathrm{O}_{5}$ & 0.68 \\
$\mathrm{SO}_{3}$ & 1.65 \\
& 86.09 \\
\hline
\end{tabular}

\section{Proximate and Ultimate Analysis of Coal}

A sample of coal was taken from a feed bin at the CONSOL combustion research facility for proximate and ultimate analysis by Hazen Research, Inc. Results are presented in Table V-2. 
Table V-2. Proximate and Ultimate Analysis of Coal

\begin{tabular}{|crr|}
\hline Parameter & As Received & \multicolumn{1}{c|}{ Dry } \\
\hline Proximate (wt. \%) & 1.40 & 0.00 \\
Moisture & 7.20 & 7.30 \\
Ash & 37.96 & 38.50 \\
Volatile & 53.44 & 54.20 \\
Fixed C & 100.00 & 100.00 \\
Total & & \\
& 1.90 & 1.93 \\
Sulfur & 13,889 & 14,086 \\
Btu/lb & & \\
& & \\
& 1.40 & 0.00 \\
Ultimate (wt. \%) & 77.14 & 78.24 \\
Moisture & 5.10 & 5.18 \\
Carbon & 1.21 & 1.23 \\
Hydrogen & 1.90 & 1.93 \\
Nitrogen & 7.20 & 7.30 \\
Sulfur & 6.05 & 6.12 \\
Ash & 100.00 & 100.00 \\
Oxygen & & \\
Total & & \\
\hline
\end{tabular}

* Oxygen by difference

\section{ESP Modelling}

The ADA ESP performance computer model was used to evaluate the potential improvement in particle collection that might be observed in the CONSOL pilot ESP when additives are used. The model was initialized using input data that would produce a collection efficiency of $98.6 \%$ - the actual measured efficiency for the unit. This efficiency was measured during a source test when the ESP was operating at a reduced electric field strength. The actual electrical characteristics of the ESP were used as input data for the model. In this case, a non-rapping particle reentrainment fraction of 0.20 was used (i.e., $20 \%$ of the emissions were due to non-rapping reentrainment). The model was then run, assuming that the non-rapping particle reentrainment fraction would drop to 0.0 due to additives. A collection efficiency of $99.2 \%$ was calculated for the ESP in this case. These results indicate that particle penetration is predicted to decrease from $1.4 \%$ for the "no additive" case to $0.8 \%$ for the "additive" case - a $43 \%$ decrease in emissions. This represents a significant improvement 
in ESP performance. This predicted improvement in performance will be evaluated during the pilot-scale testing phase of the program. A summary of the ESP model results is presented in Table V-3.

Table V-3. ADA ESP Model - Summary of Operating Conditions and Results

\begin{tabular}{|c|c|c|}
\hline & Base Case & With Additive \\
\hline $\begin{array}{l}\text { Operating Conditions } \\
\text { SCA } \\
\text { Non-Rap Reentrainment Fraction } \\
\text { Gas Sneakage Fraction } \\
\text { Gas Velocity Sigma }\end{array}$ & $\begin{array}{c}240 \mathrm{ft}^{2} / \mathrm{kacfm} \\
0.20 \\
0.10 \\
0.10\end{array}$ & $\begin{array}{c}240 \mathrm{ft}^{2} / \mathrm{kacfm} \\
0.20 \\
0.10 \\
0.10\end{array}$ \\
\hline $\begin{array}{l}\text { Mass Loading } \\
\text { Inlet Loading } \\
\text { Outlet Loading } \\
\text { Inlet MMD } \\
\text { Outlet MMD }\end{array}$ & $\begin{array}{l}1.32 \mathrm{E}-3 \mathrm{~kg} / \mathrm{m}^{3} \\
1.87 \mathrm{E}-5 \mathrm{~kg} / \mathrm{m}^{3} \\
6.90 \mu \mathrm{m} \\
3.04 \mu \mathrm{m}\end{array}$ & $\begin{array}{l}1.32 \mathrm{E}-3 \mathrm{~kg} / \mathrm{m}^{3} \\
1.05 \mathrm{E}-5 \mathrm{~kg} / \mathrm{m}^{3} \\
6.90 \mu \mathrm{m} \\
3.50 \mu \mathrm{m}\end{array}$ \\
\hline $\begin{array}{c}\text { ESP Performance } \\
\text { Efficiency } \\
\text { Penetration }\end{array}$ & $\begin{array}{c}98.583 \% \\
1.417 \%\end{array}$ & $\begin{array}{c}99.207 \% \\
0.793 \%\end{array}$ \\
\hline
\end{tabular}




\section{Waste Characterization}

Radian Corporation is performing waste characterization testing of a sample of fly ash collected in the bench-scale ESP during a test when additive " $C$ " was being injected. Although the analysis is still in progress at the time of writing this Topical Report, preliminary results of metals analysis are available. Table VI-1 summarizes the data. Results show that the measured concentrations of the metals are well below the standards established by the Environmental Protecion Agency for declaring the fly ash as a hazardous waste.

Table VI-1. Preliminary Analysis of TCLP* Metals

\begin{tabular}{|ccc|}
\hline $\begin{array}{c}\text { Metal } \\
\text { Specie }\end{array}$ & $\begin{array}{c}\text { Measured Concentration } \\
\mathrm{mg} / 1\end{array}$ & $\begin{array}{c}\text { TCLP Limit } \\
\mathrm{mg} / 1\end{array}$ \\
\hline Arsenic & 0.337 & 5.0 \\
Barium & 0.492 & 100 \\
Cadmium & 0.0321 & 1.0 \\
Chromium & 0.474 & 5.0 \\
Lead & <DL+ & 5.0 \\
Silver & <D + & 5.0 \\
\hline
\end{tabular}

* TCLP $=$ Toxicity Characteristic Leaching Procedure

+ The measured concentration was less than the limit of detection of the analytical test method. 


\section{Economic Analysis}

\section{Introduction/Summary}

A rough, preliminary cost analysis was performed to determine if, due to particularly excessive potential costs, any of the candidate gas conditioning chemicals and/or technologies should be eliminated early. The following summarizes the results of the preliminary economic analysis. Capital and operating and maintenance (O\&M) costs for the various technologies were developed and then compared using a simple life cycle cost model. The primary inputs to this preliminary analysis from the bench-scale testing were the feed rates that were effective for each chemical. Since this analysis was done in parallel with the initial bench-scale testing, the economics could not be normalized in terms of the ESP performance enhancement of each chemical.

The chemicals vary significantly in their methods of shipment, delivery and handling. Some chemicals are available as liquids; whereas, others may also or only be available as bulk and/or bagged solids. Therefore, it was expected that the material delivery and handling systems and their capital and O\&M costs would have a significant effect on the economic comparison of the alternatives. So that the costs could be compared, conceptual designs were developed for each material handling scenario.

\section{Summary of Results}

The results of this preliminary economic analysis show that flue gas conditioning with the least expensive, and apparently the most effective, chemical (Chemical C) is quite cost competitive with installing new ESP capacity or with other proprietary flue gas conditioning processes that may not be nearly as effective.

At the level of accuracy of this preliminary pre-screening analysis, however, the costs of the various chemicals and their respective feed rates proved to have an overwhelming effect on the economics of this technology. For example, one of the most expensive chemicals (Chemical A at $\$ 8,000 /$ ton) at its highest feed rate anticipated prior to the bench-scale test program (at $1 \%$ of the ash loading to the precipitator) adds roughly $\$ 8$ per ton of coal consumed. This is due to the cost of the additive alone without considering the cost of the handling, storage and injection system or time-value of money. 
In contrast, an actual field trial of a competitor's proprietary chemical and injection process used to promote ash cohesiveness was estimated to add approximately $\$ 0.35$ to $\$ 0.50$ per ton of coal fired over the two-year period during which the chemical was to be used. Note that this estimate was made irrespective of the effectiveness of the chemical; and indeed the trial was not able to demonstrate any precipitator performance enhancement.

Fortunately, bench-scale testing has shown that the cheapest chemical is very effective at injection rates that are significantly lower than originally anticipated at the outset of the program. This injection technology thus becomes cost competitive with other proprietary processes, which as described above may not actually be effective. Table VII- 1 below compares to the other proprietary process the complete levellized costs (over a 30-year plant life) of the cheapest chemical at various feed rates and its associated capital and O\&M requirements.

Table VII-1. Levellized Cost Of Injection Process Using Chemical C At Various Feed Rates

\begin{tabular}{|c|c|c|c|c|}
\hline & $\begin{array}{c}\text { Proprietary } \\
\text { Process }\end{array}$ & $\begin{array}{c}\text { Chemical C } \\
@ 0.1 \%\end{array}$ & $\begin{array}{c}\text { Chemical C } \\
@ 0.01 \%\end{array}$ & $\begin{array}{c}\text { Chemical C } \\
@ 0.005 \%\end{array}$ \\
\hline $\begin{array}{l}\text { Chemical Cost } \\
\text { \$/ton Coal }\end{array}$ & $\begin{array}{c}\$ 35,300 / \mathrm{mo}^{*} \\
0.50 \bullet\end{array}$ & $\begin{array}{c}\$ 1.90 / \mathrm{lb}+ \\
0.85\end{array}$ & $\begin{array}{c}\$ 1.90 / \mathrm{lb}+ \\
0.39\end{array}$ & $\begin{array}{c}\$ 1.90 / 1 b+ \\
0.36\end{array}$ \\
\hline
\end{tabular}

* Monthly cost of chemical and equipment lease. Does not include escalation over 30-year plant life.

+ Current cost per pound of highly refined chemical.

- Does not include escalation over 30-year plant life.

- Levellized cost over 30-year plant life.

Table VII-1 demonstrates that as the chemical injection rate comes down the capital equipment costs for the chemical mixing and injection equipment become more significant. However, capital cost is influenced by the cost of the chemical and its injection rate due to their effects on the inventory capital and pre-production costs (estimated as a percentage of "consumables", which overwhelmingly comprise the chemical) and on the size of storage silos or buildings. Therefore a goal for future testing should be to minimize injection rates and to investigate the use of a less-refined chemical, which should be more economical. Delivery of the chemical as a liquid should be investigated since liquid material handling systems can require less capital and O\&M labor.

Significant economies are possible by investigating in more detail alternative and cheaper methods to ship, unload, store and process the chemical. Therefore, future economic 
analyses should include a more detailed (and accurate) design and capital cost development for the material handling and injection systems. Note also that the estimation and economic methods used here are conservative and incorporate substantial contingencies that can be reduced or eliminated once additional data is available from further testing. Further ecunomy will result if a standard modular design can be developed to effectively share the cost of process equipment development over the multitude of sites in which the chemical could be used.

\section{Methodology}

This preliminary economic analysis was performed to determine if, due to particularly excessive potential costs, any of the candidate gas conditioning chemicals and/or technologies should be eliminated early. To do this, the capital and operating and maintenance (O\&M) costs for the various technologies were developed and then compared using a simple life cycle cost model.

The methodology used is consistent with economic analyses conducted by the Electric Power Research Institute (EPRI). In this way the results calculated here can be compared with generally-accepted results for conventional PC-fired power plants. The approach is to calculate capital and operating and maintenance (O\&M) costs based on simplified cost models developed and published in the two references. A 250-MW (net) generating unit is the basis for equipment sizing and cost development so that results from this analysis can be compared directly to recent results from EPRI studies.

To account for the time-value of money, EPRI's approach is to compare the total levellized busbar costs of the alternatives over the life of a plant. That is, the total capital and O\&M costs are calculated for each alternative under consideration and levellized (i.e., spread out over the plant's life) in terms of mills $/ \mathrm{kW}$-hr of electricity produced.

The capital costs are calculated and expressed here as total capital requirement in terms of $\$ / \mathrm{kW}$. In general, total capital requirement includes the following components:

- Process Capital, which for most cases in this analysis, includes primarily the installed cost of the equipment required to receive, unload, store, mix, meter and inject chemical into the flue gas upstream of an existing electrostatic precipitator (ESP). For a complete particulate control system (e.g., an ESP), process capital includes the cost of the particulate collector, its associated 
ductwork, the fly ash handling system and the differential cost for the portion of the ID fan required to overcome the pressure drop across the collector.

- Total Plant Cost, which includes all process capital components with appropriate factors added to account for general facilities, engineering and home office fees, process contingencies and project contingencies.

- The Total Plant Investment, which includes all of the above and the allowance for funds used during construction, pre-production costs and inventory capital.

Capital costs for the chemical injection systems are complete for the installed equipment. Note that for a complete particulate control system (e.g., an ESP) this cost methodology considers differential costs. That is, although most costs are complete, the cost for ductwork and the ID fan are differential costs and represent not complete systems but rather the incremental costs over and above that required for a power plant without particulate control. Also, note that capital costs expressed in terms of $\$ / \mathrm{kW}$ should not be generalized and used in comparison to units of different generating capacity. However, such terms are quite instructive for comparisons here since all units are assumed to have the same net generating capacity $(250 \mathrm{MW})$.

O\&M costs are calculated as first year costs in terms of $\$ / \mathrm{kW}-\mathrm{yr}$ and then levellized over the life of the plant. O\&M costs include the following components:

- Fixed O\&M Costs, which include O\&M labor and materials and administration and support labor. These costs are assumed to remain constant despite variations in unit capacity factor.

- Variable O\&M Costs, which include, for the purposes of this study, primarily;

- power requirements for the chemical unloading, storage, mixing and injection system, including; blowers, pumps, mixers and heat tracing and process heating.

- chemical usage and other consumables such water.

- for a complete ESP installation; power requirements for the ID fan to overcome the pressure drop across the collector, hopper heaters, fly ash conveying system, T-R sets, support bushing heaters and purge air systems and rapper motors.

- for a complete ESP installation fly ash disposal cost. 
For the purpose of this preliminary analysis, O\&M costs for the ESP were neglected since at this stage in the testing, the absolute effectiveness of each chemical and injection rates and the effects on T-R set power could not be determined.

The primary economic parameters assumed for this study, and which are consistent with the referenced EPRI economic comparisons, follow in Table VII-2.

Table VII-2. Economic Parameters

\begin{tabular}{|lc||}
\hline Commercial operating date & January, 1991 \\
Present value date & January, 1991 \\
Construction period & 3 years* \\
$250 \mathrm{MW}$ Unit & 30 years \\
Total life & $9.8 \% / \mathrm{yr}$ \\
Discount rate after tax & $5.0 \% / \mathrm{yr}$ \\
General rate of inflation & $0.3 \% / \mathrm{yr}$ \\
Real escalation rate & $0 \% / \mathrm{yr}$ \\
Power & 0.165 \\
Other & $65 \%$ \\
Capital levellization factor & \\
Design capacity factor & \\
\hline
\end{tabular}

* Typical construction period for a complete particulate control system.

Other economic factors and the economic methodology are described in detail in the references.

\section{Injection System Process Design and Operating Parameters}

The chemicals vary significantly in their methods of shipment, delivery and handling. Some chemicals are available as liquids; whereas, others may also or only be available as bulk and/or bagged solids. Therefore, it was expected that the material delivery and handling systems and their capital and O\&M costs would have a significant effect on the economic comparison of the alternatives. So that the costs could be developed and compared, conceptual designs were developed for each material handling scenario.

Figure VII-1 is a process flow diagram that presents the basic conceptual design for the chemical injection process. Material is delivered either dry, in bulk or in bags, by tank truck or in a concentrated liquid state by tank truck. According to EPRI criteria a 90-day storage capacity is provided for the chemical: either silos for bulk dry delivery, a small warehouse building for bagged chemical, or storage tanks for liquid delivery. The chemical is then fed 
upon demand to the mixing station where it is mixed to the proper concentration. The mixture is then fed to the pump skids for pumping at the appropriate concentration and rates to the injection lances at the flue gas ductwork upstream of the ESP.

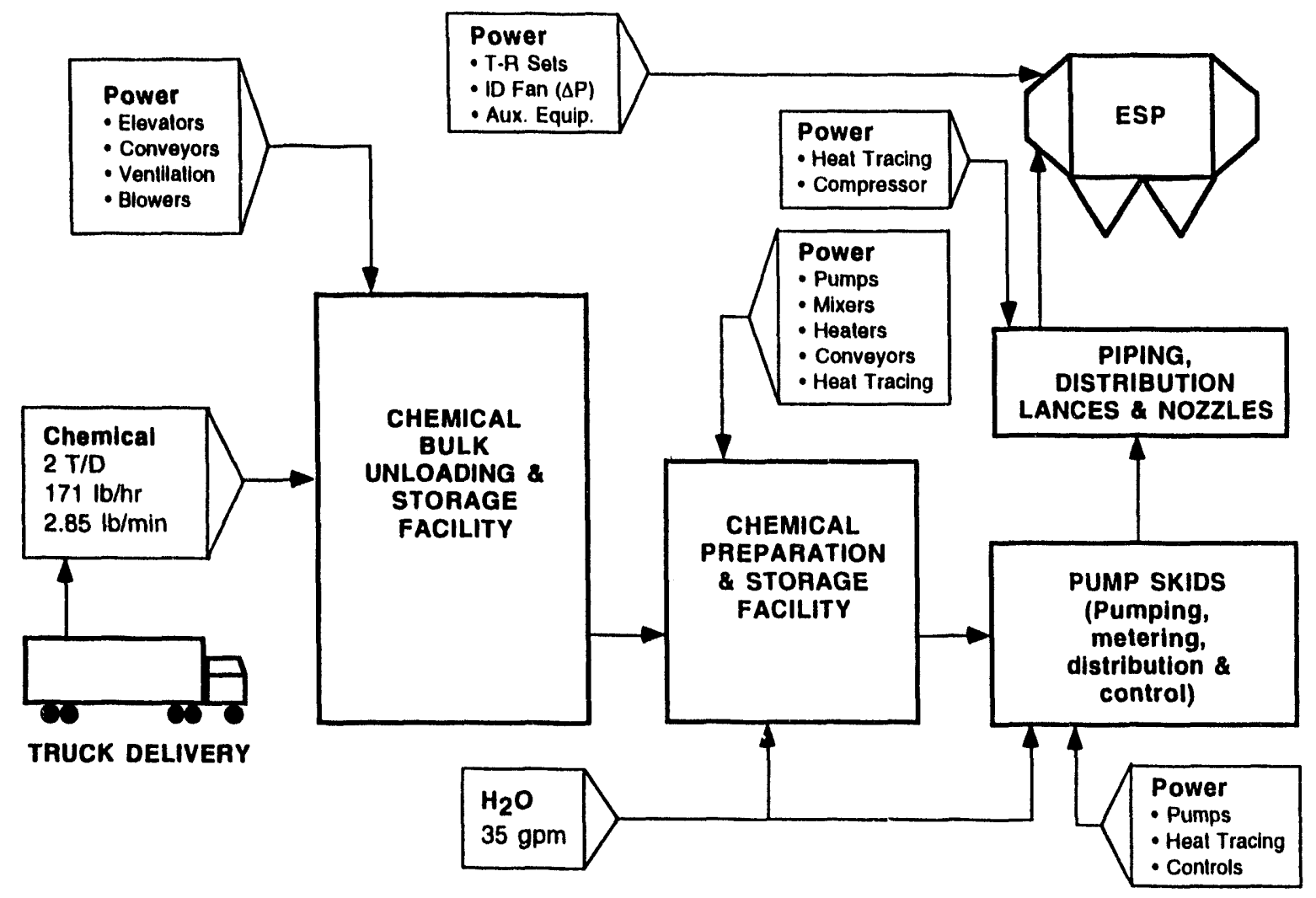

Figure VII-1. Process flow diagram.

Appendices A and B describe in detail the conceptual designs, the capital cost estimates and the operating parameters and consumables rates for the dry chemical and liquid chemical systems, respectively, for unloading, storing and preparing/mixing the conditioning agents. It was assumed that once the bulk chemicals were mixed, the pump skids and injection lance system for delivery of the chemical into the flue gas would be the same for any of the chemicals. A detailed system description and the capital cost estimate for the pump skid and piping/injection lance system is presented in Appendix C.

The following summarizes the installed equipment cost for the dry and liquid chemical unloading, storage and mixing systems: 
- $\quad$ Dry Chemical Feed (Truck Delivery)

- Dry Chemical Feed (Bag Delivery)

- $\quad$ Liquid Chemical Feed (20\% Solution)

- $\quad$ Liquid Chemical Feed (45\% Solution)

- $\quad$ Pump Skids \& Piping/Injection Lances
$\$ 240,000$

$\$ 190,000$

$\$ 85,000$

$\$ 60,000$

$\$ 66,000$

As can be seen, truck delivery of dry chemical requires the highest capital investment; although, within the accuracy of this analysis, the cost of such a system is quite close to that of the dry chemical system using bag delivery. The liquid chemical systems promise greater economy based on capital cost alone. However, as will be seen in the economic analysis below, only the most expensive chemical is deliverable in liquid form (based on current information) and the capital savings become insignificant.

The following Table VII-3 presents the costs and some properties of the various chemicals as considered in this analysis.

TABLE VII-3. Additive Characteristics

\begin{tabular}{|cccc||}
\hline Product & Memperature & Handling & Characteristics \\
\hline A & Hot $\left(200^{\circ} \mathrm{F}\right)$ & $\begin{array}{c}\text { Powder, Shipped in } 50 \mathrm{lb} \text {. bags. } \\
\text { Store in cool, dry area. }\end{array}$ & $\$ 8,000$ \\
B & Hot or Cold & $\begin{array}{c}\text { Powder, Shipped in } 110 \mathrm{lb} \text {. Containers } \\
\text { or by truckload. Store in } \\
\text { cool, dry area. Can also be shipped } \\
\text { as a 20\% or 45\% solution. }\end{array}$ & $\$ 9,120$ \\
C & Hot or Cold & $\begin{array}{c}\text { Powder, Shipped in 50 lb. aluminum } \\
\text { foil-lined bags. Store in cool, } \\
\text { dry area. }\end{array}$ & $\$ 3,800$ \\
D & Hot or Cold & $\begin{array}{c}\text { Powder, Shipped in 50 lb. bags. } \\
\text { Store in cool, dry area. }\end{array}$ & $\$ 8,000$ \\
\hline
\end{tabular}




\section{Economic Results}

Figure VII-2 compares the total levellized costs for Chemicals A, B, and C at various injection rates. Also included for comparison is the cost of a new ESP with a specific collection area (SCA) of $400 \mathrm{ft}^{2} / \mathrm{kacfm}$. This cost was developed by Gaikwad and Sloat (1992) and represents a new plant. However, retrofit ESP capacity can cost as much or more, even if at a smaller SCA, due to retrofit difficulties and costs for extensive ductwork and ash system modifications.

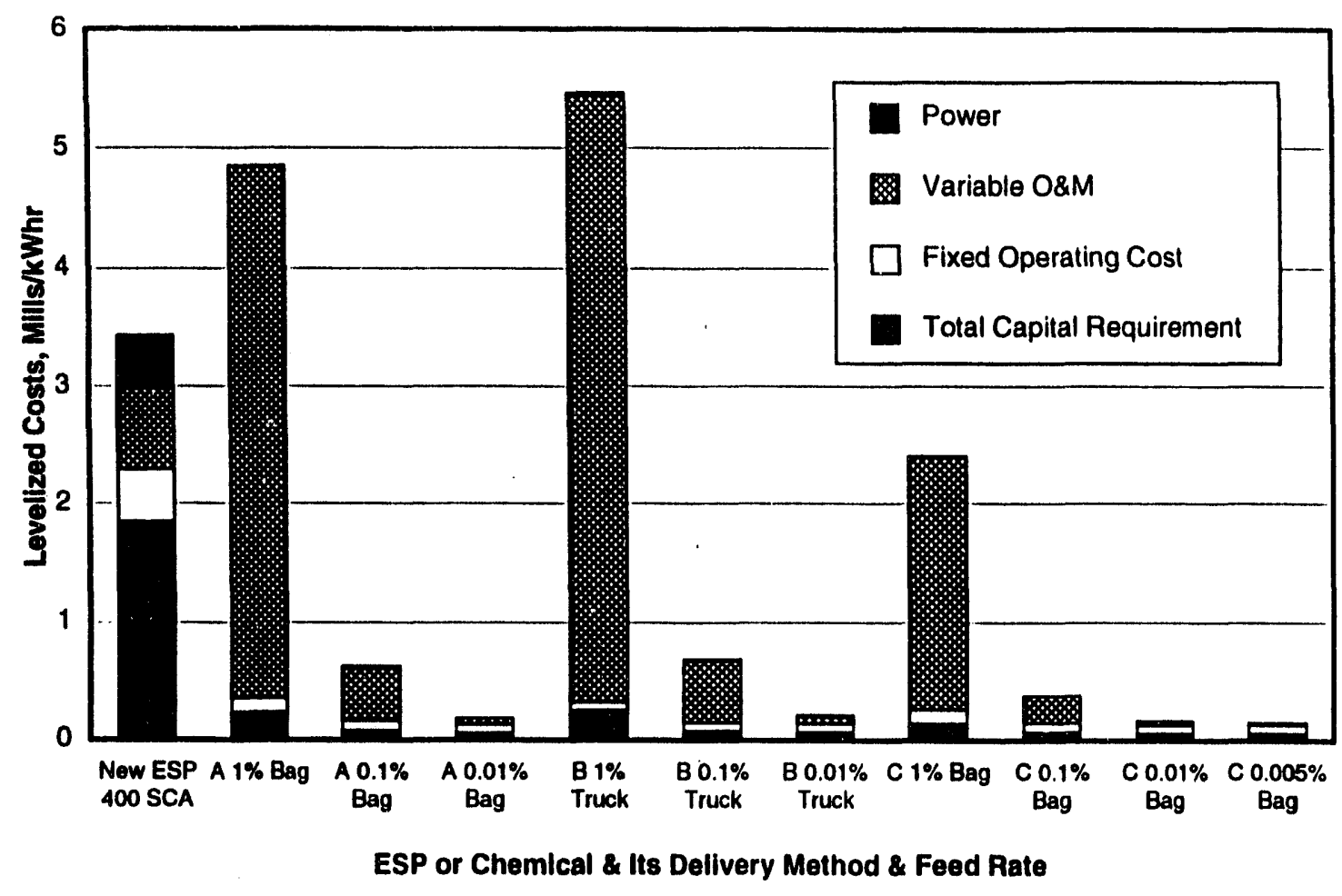

Figure VII-2. Levellized cost comparison of various chemicals and feed rates and a new 400 SCA ESP.

The first detail to note is the overwhelming effect on the economics of any conditioning system imposed by the cost of the chemical and its injection rate. As shown in Figure VII-2, the two most expensive chemicals (Chemicals A \& B) at the highest feed rates anticipated prior to testing are not even competitive with a new ESP installation. As shown in the bar chart, the largest cost component is the variable O\&M cost, which for these chemicals is essentially $100 \%$ attributable to the cost of the chemical. 
The cost of the chemical and its feed rate also affect the capital cost in surprising ways. As would be expected, the feed rate affects the size and thus the cost of the chemical storage and handling equipment. However, for the EPRI methodology used here, pre-production costs and inventory capital are calculated as a percentage of the total plant investment and one month of variable O\&M costs, respectively. Both are affected by the cost of the chemical and its injection rate.

Figure VII-2 clearly demonstrates that the least expensive chemical (Chemical C) is more economical than a new ESP, even at the highest anticipated feed rate. Fortunately, bench-scale testing has demonstrated that Chemical $\mathrm{C}$ is effective at very low injection rates. This suggests, as described above in Table VII-1 and the Summary of Results, that Chemical C and this ESP performance enhancement strategy is also cost competitive with other proprietary chemicals, which as described above may not actually be effective.

The bar chart in Figure VII-3 presents the same data as in Figure VII-2 above, but only for cost competitive chemicals and/or feed rates so that a more detailed comparison can be made. Also presented below is Table VII-4, which compares detailed levellized operating cost breakdowns for a new ESP, Chemical B at the highest feed rate (1\%) and Chemical $C$ at an effective feed rate $(0.01 \%)$ to demonstrate further the effect of chemical cost and feed rate on the total levellized cost. Table VII-5 compares capital cost breakdowns of these same options. 


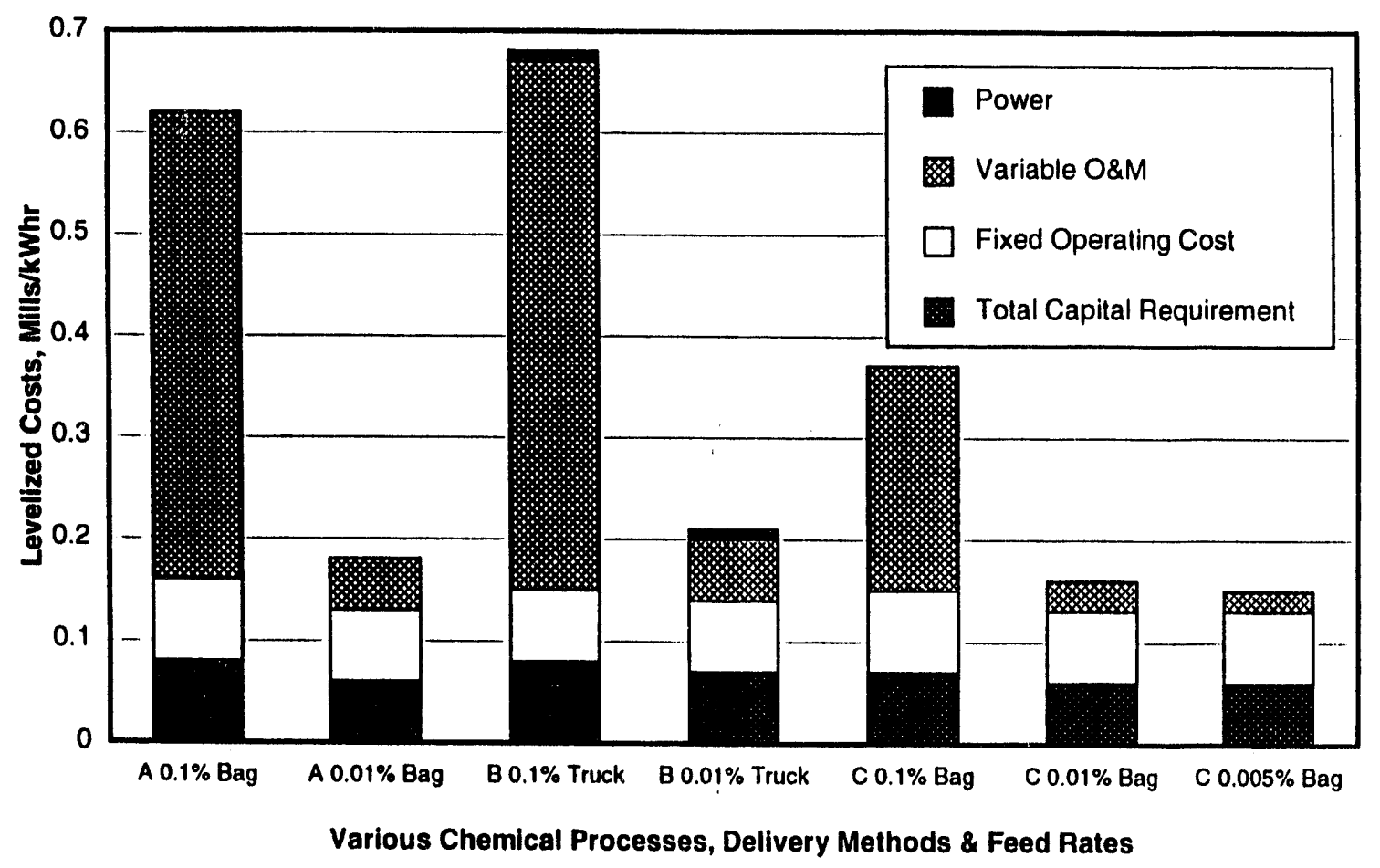

Figure VII-3. Levellized costs of various chemical injection processes using different delivery methods and feed rates.

Table VII-4. First Year and Levellized O\&M Costs

\begin{tabular}{|c|c|c|c|c|c|c|}
\hline & \multicolumn{2}{|c|}{ New ESP } & \multicolumn{2}{|c|}{$\begin{array}{c}\text { Chem. B } \\
\text { @ } 1 \%\end{array}$} & \multicolumn{2}{|c|}{$\begin{array}{l}\text { Chem. C } \\
@ 0.01 \% \text {. }\end{array}$} \\
\hline & $18 t$ Year & Level zd & 1st Year & Level'zd & 1st Year & Level'zd \\
\hline \multicolumn{7}{|l|}{ Fixed Operating Costs } \\
\hline Operating Labor & 0.24 & 0.07 & 0.12 & 0.03 & 0.12 & 0.03 \\
\hline \multirow[t]{2}{*}{ Maintenance Labor } & 0.21 & 0.06 & 0.06 & 0.02 & 0.06 & 0.02 \\
\hline & 0.31 & 0.09 & 0.01 & 0.00 & 0.01 & 0.00 \\
\hline Admin \& Support Labor & $\underline{0.14}$ & $\underline{0.04}$ & $\underline{0.05}$ & $\underline{0.02}$ & $\underline{0.05}$ & $\underline{0.02}$ \\
\hline TOTAL FIXED & 0.90 & 0.27 & 0.24 & 0.07 & 0.24 & 0.07 \\
\hline \multicolumn{7}{|l|}{ Variable Operating } \\
\hline Power & 2.11 & 0.65 & 0.02 & 0.01 & 0.01 & 0.00 \\
\hline Ash Disposal & 1.74 & 0.51 & 0.00 & 0.00 & 0.00 & 0.00 \\
\hline Conditioning Chemical & 0.00 & 0.00 & 17.31 & 5.12 & 0.07 & 0.02 \\
\hline Water & $\underline{0.00}$ & $\underline{0.00}$ & $\underline{0.03}$ & $\underline{0.01}$ & $\underline{0.03}$ & $\underline{0.01}$ \\
\hline TOTAL VARIABLE & 3.84 & 1.16 & 17.36 & 5.14 & 0.11 & 0.03 \\
\hline
\end{tabular}


Table VII-5. Capital Costs

\begin{tabular}{|c|c|c|c|}
\hline & $\begin{array}{l}\text { New ESP } \\
\$ / \mathrm{kW}\end{array}$ & $\underset{\$ / \mathrm{kW}}{\text { Chem. B }} 1 \%$ & Chem. $\underset{\$ / \mathrm{kW}}{\mathrm{C}} 0.01 \%$ \\
\hline $\begin{array}{l}10 \text { Collector and Hopper } \\
20 \text { Ductwork } \\
30 \text { Fly Ash Handling System } \\
40 \text { Differential Costs }\end{array}$ & $\begin{array}{r}32.06 \\
1.01 \\
6.25 \\
0.74\end{array}$ & $\begin{array}{l}1.27 \\
0.00 \\
0.00 \\
0.00\end{array}$ & $\begin{array}{l}1.26 \\
0.00 \\
0.00 \\
0.00\end{array}$ \\
\hline $\begin{array}{l}\text { TOTAL PROCESS CAPITAL (TPC) } \\
\text { General Facilities @ } 1 \% \text { of TPC } \\
\text { Eng. Fees @ 5-15\% of TPC } \\
\text { Project Contingency @ 25\% TPC } \\
\text { Process Contingency* }\end{array}$ & $\begin{array}{r}40.06 \\
0.40 \\
2.00 \\
8.01 \\
0.00\end{array}$ & $\begin{array}{l}1.27 \\
0.01 \\
0.19 \\
0.25 \\
0.25\end{array}$ & $\begin{array}{l}1.26 \\
0.01 \\
0.19 \\
0.25 \\
0.25\end{array}$ \\
\hline $\begin{array}{l}\text { TOTAL PLANT COST } \\
\text { AFDC }\end{array}$ & $\begin{array}{r}50.47 \\
3.18\end{array}$ & $\begin{array}{l}1.98 \\
0.12\end{array}$ & $\begin{array}{l}1.97 \\
0.12\end{array}$ \\
\hline $\begin{array}{l}\text { TOTAL PLANT INVESTMENT } \\
\text { Pre-production Costs } \\
\text { Inventory Capital }\end{array}$ & $\begin{array}{r}53.65 \\
1.07 \\
0.27\end{array}$ & $\begin{array}{l}2.10 \\
2.29 \\
4.38\end{array}$ & $\begin{array}{l}2.10 \\
0.08 \\
0.02\end{array}$ \\
\hline TOTAL CAPITAL REQUIREMENT & 55.00 & 8.78 & 2.20 \\
\hline
\end{tabular}

* Process Contingency @ 0\% for ESP and 20\% for chemical conditioning process based on EPRI criteria depending upon commercial development of process.

The bar chart in Figure VII-3 and data in Table VII-4 demonstrate that for Chemical C, the fixed operating costs become significant. These involve primarily the labor for operating and maintaining the material handling system. Liquid chemical systems in general require less maintenance and operating labor. Additionally, since liquid material handling systems require less capital investment, the potential for receiving and storing Chemical $\mathrm{C}$ or an equivalent less expensive chemical as liquids should be investigated. Note, however, that if one of the more expensive chemicals and/or higher feed rates are required, the capital and fixed O\&M cost savings for a liquid system become less significant.

\section{Recommendations for Future Testing and Economic Analysis}

This analysis represents a preliminary cost estimate based on early bench-scale test results. Further, more detailed testing at the bench-scale and a larger scale will allow more accurate cost comparisons to be made. To facilitate more accurate analyses for future economic comparisons, the following should be considered in additional testing: 
- Optimize feed rates for most promising chemical(s).

- Investigate feasibility and effects of using less-refined/expensive form(s) of chemicals.

- If possible, develop measures and/or models of ESP efficiency improvements for the most promising chemical(s) for varying feed rates. This will allow normalizing system costs to equivalent ESP performance enhancements from various methods and/or chemicals.

- Investigate the feasibility of delivering and storing (preserving) effective (less expensive) chemical(s) in liquid form to reduce capital and operating/maintenance labor costs.

- Determine if any promising chemicals exhibit difficulties in handling, storing or mixing that would require special material handling equipment.

The economic modeling methodology should be fine tuned in the following ways for future analyses:

- Refine and adapt system designs for material handling and injection systems for each chemical.

- Include analysis for liquid chemical system(s) if applicable for any of the economical chemicals; Refine liquid system design and consider alternative delivery storage system.

- Refine economic parameters, such as;

- reduce construction time for additive systems to more realistic schedule of six months to a year.

- investigate reduction of chemical storage requirements.

- investigate validity of reducing estimating factors for pre-production costs and inventory capital.

- refine project and process contingencies for chemical injection processes.

- Develop more accurate capital cost for pump skids and injection lances/piping.

- Compare chemical injection processes to more ESP upgrade options and normalize based on performsnce improvement, where possible;

- retrofit ESP capacity. 
- dual $\mathrm{SO}_{3} / \mathrm{NH}_{4}$ gas conditioning.

- other proprietary chemical processes.

- digital controls or other enhancements.

- Compare chemical injection processes to ESP upgrade options for different (shorter) remaining plant lives.

- $\quad$ Refine estimates of fixed O\&M labor and materials for dry systems and for liquid systems (if feasible).

- Include T-R Set Power.

\section{References}

Gaikwad, R.P. and D.G. Sloat (1992). Economic Evaluation of Particulate Control Technologies - Volume 1: New Units, EPRI TR-100798, Volume 1, September.

Scheck, R.W., R.R. Mora, V.H. Belba and F.A. Horney (1985). Economics of Fabric Filters and Electrostatic Precipitators - 1984, EPRI CS-4083, June. 
Appendices 


\section{Appendix A - Dry Chemical Delivery, Storage and Handling System Description and Cost Estimates}

\subsection{Scope}

The Dry Chemical Feed System is designed to receive dry chemical delivered in bulk by truck, or alternatively in bags, store the chemical, and feed a solution of the chemical to the process at a controlled rate. The system and its alternative are depicted in Figures A-1 and A2 , respectively. The equipment required to handle the chemical feed is detailed on the Equipment Summary Tables included in this appendix. The system includes all equipment and controls necessary for the feed of the chemical from the truck unloading to the discharge of the feed pumps.

\subsection{Design Basis}

The following criteria have been established for the design of this system:

$\begin{array}{ll}\text { Dry Chemical Feed Rate } & 2 \text { tons/day } \\ \text { Storage Required } & 90 \text { days (30 days alternate) } \\ \text { Chemical Solution Temperature } & \left.200^{\circ} \mathrm{F} \text { (Alternate } 1\right) \\ & \left.60^{\circ} \mathrm{F} \text { (Alternate } 2\right) \\ \text { Feed Solution Quality } & 20 \% \text { (By weight) } \\ \text { Bulk Chemical Density } & 0.3 \text { to } 0.5 \mathrm{gm} / \mathrm{cc} \\ \text { Chemical Delivery } & \begin{array}{l}\text { Truck }(40,000 \mathrm{lbs}) \\ \text { (Alternate }- \text { Bags) }\end{array}\end{array}$

\subsection{System Description}

\subsection{Truck Delivery}

The system is designed to receive truck load quantities of dry chemical. The shipping limit for the truck transport on highways is $40,000 \mathrm{lbs}$, and the system is designed on this basis. The dry chemical can also be shipped in $110 \mathrm{lb}$ or $50 \mathrm{lb}$ bags, and a scheme has been developed for this case. 


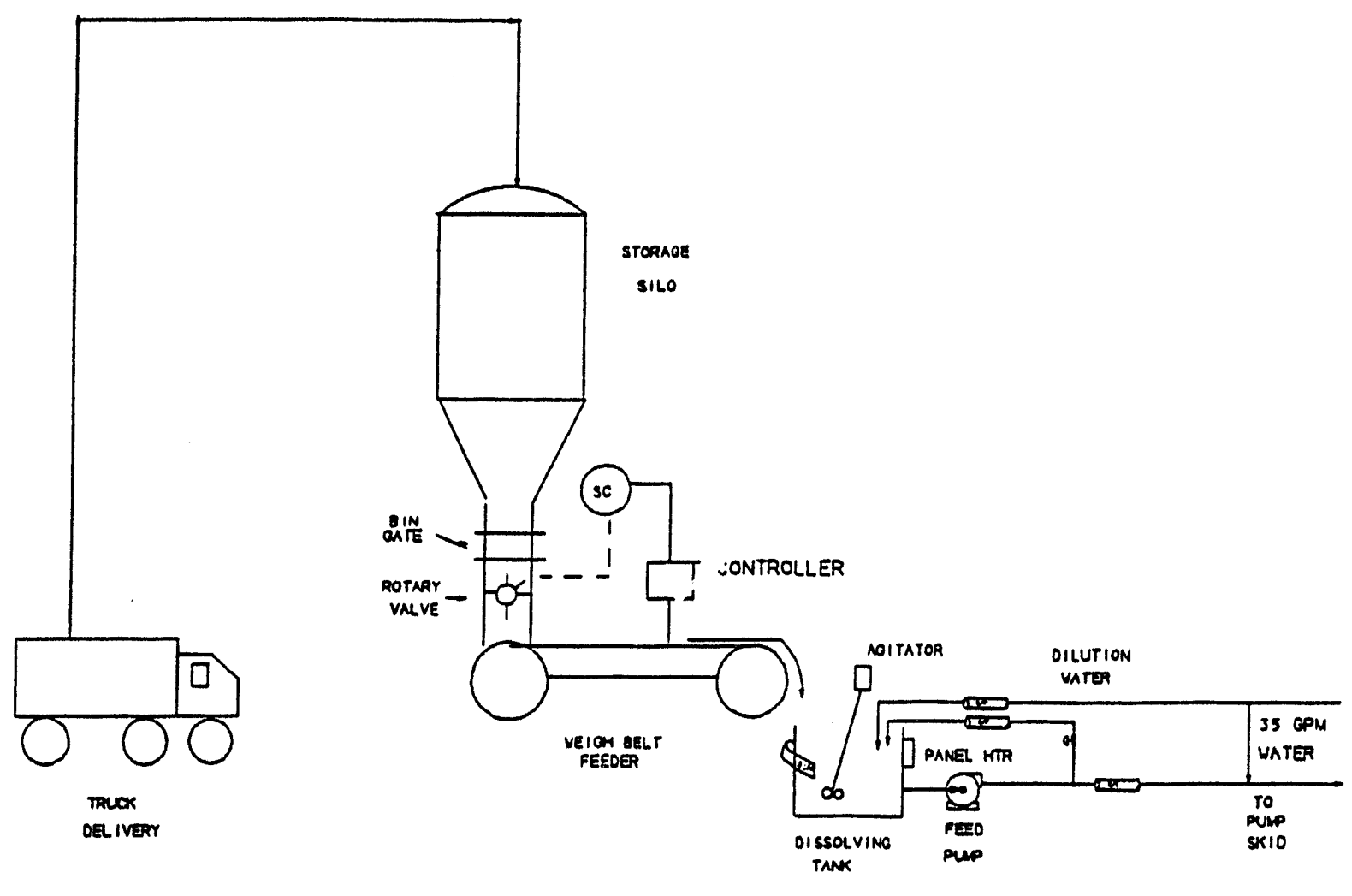

Figure A-1. Dry chemical unloading, storage, and mixing system - tank truck delivery. 


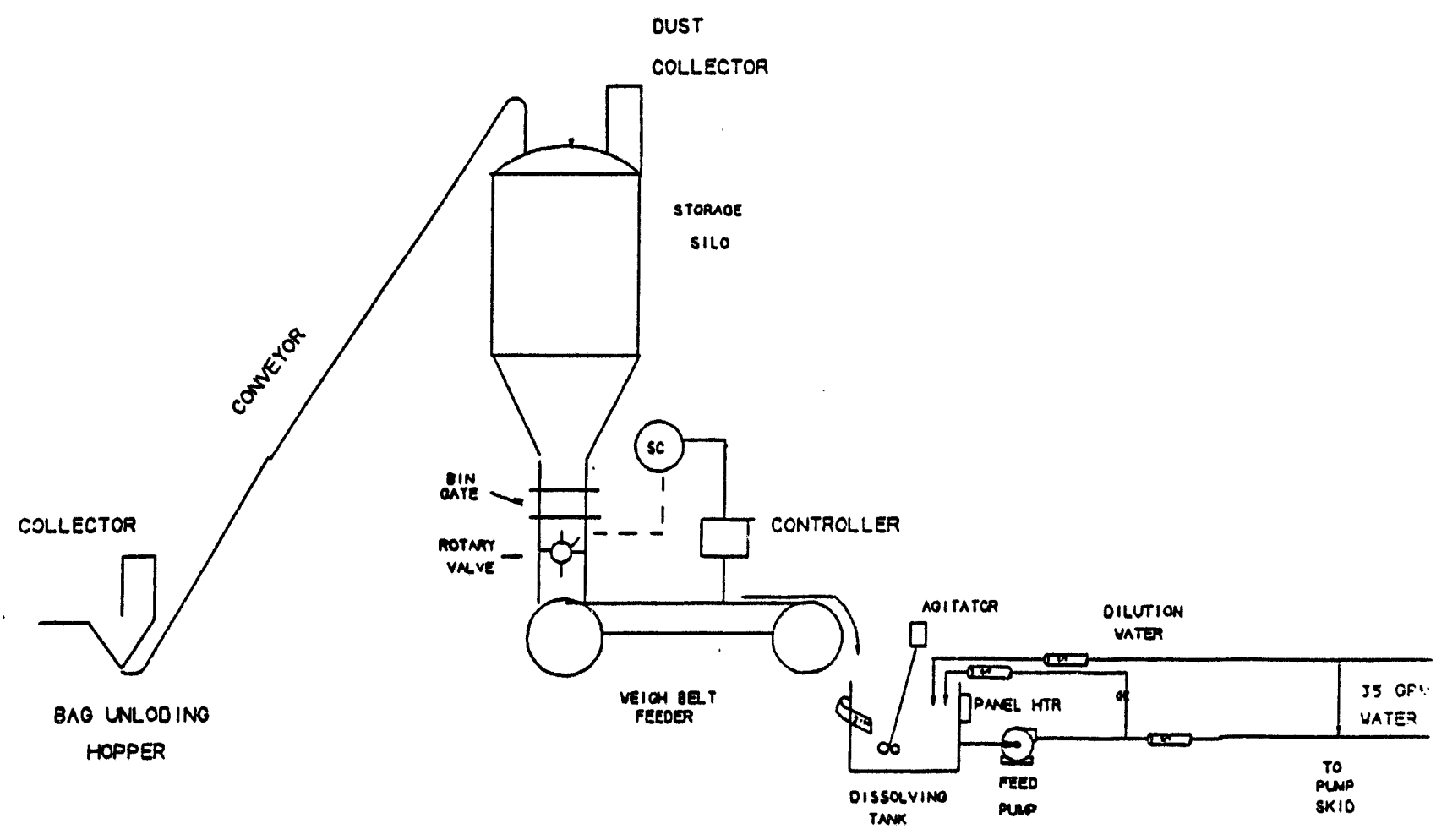

Figure A-2. Dry chemical unloading, storage, and mixing system - bag delivery. 
The truck will be equipped with blowers to transport the chemical from the truck to the chemical silo. A flexible hose connection is provided for the truck hookup; the transport piping from the truck hookup to the top of the silo is hard piped. A relief valve is supplied on the truck to prevent overpressure of the truck during the transport operation. The silo has a bin vent to purge the motive air to atmosphere minimizing back pressure. The bin vent is equipped with dust control. A high level alarm and high-high level alarm are provided on the silo to alarm the operator as the silo fills. The high alarm is set at $2 \mathrm{ft}$ from the top while the high-high alarm is set at $1 \mathrm{ft}$ from the top. The level signal can be transmitted for remote monitoring, if desired. The high-high level can also shut down the blowers.

Normally the truck unloading continues until the truck is emptied. The truck is weighed entering and leaving to determine the quantity of chemical delivered.

If the chemical is received in bags, an operator must manually load the bags into the storage silo. Equipment is supplied to facilitate this operation, as illustrated in Figure A-2. A bag dump station and a screw conveyor are provided for the bag unloading. The bag dump station consists of a small storage bin with a table mounted on top which allows the operator to set a bag down, split the bag open, and dump the contents into the hopper. The bottom of the hopper is connected to a screw conveyor to route the material to the top of the Storage Silo. The conveyor speed can be adjusted to convey the chemical at approximately the same rate the bags are manually loaded.

\subsection{Storage Silo}

As shown on Figure A-1, the dry chemical is stored in a silo and then supplied to a Dissolving Tank for feed to the process. The Silo is constructed of carbon steel, and has been sized to hold 90 days of chemical at a feed rate of 2 tons/day. Three Silos have been included each sized for $12^{\prime} 0^{\prime \prime}$ Diameter X $48^{\prime} 0^{\prime \prime} \mathrm{Ht}$; Figure A-3 illustrates the physical dimensions of each Silo. One common Silo sized at $20^{\prime} 0^{\prime \prime} \mathrm{X} 48^{\prime} 0^{\prime \prime}$ could be provided. A cost savings is attained with one silo as quantified in Section 4, but no redundancy is provided.

The cone on the bottom of the Silo is sloped at a $60^{\circ}$ angle to allow the dry chemical to slide to the rotary valve at the entrance to the weigh belt feeder. The side of the cone can be equipped with vibrators or a bin activator to minimize caking of the chemical and assist in the feed. The particle size (and other properties) of the chemical will determine whether a vibrator or bin activator is required. The smaller particle sizes tend to bind more. 


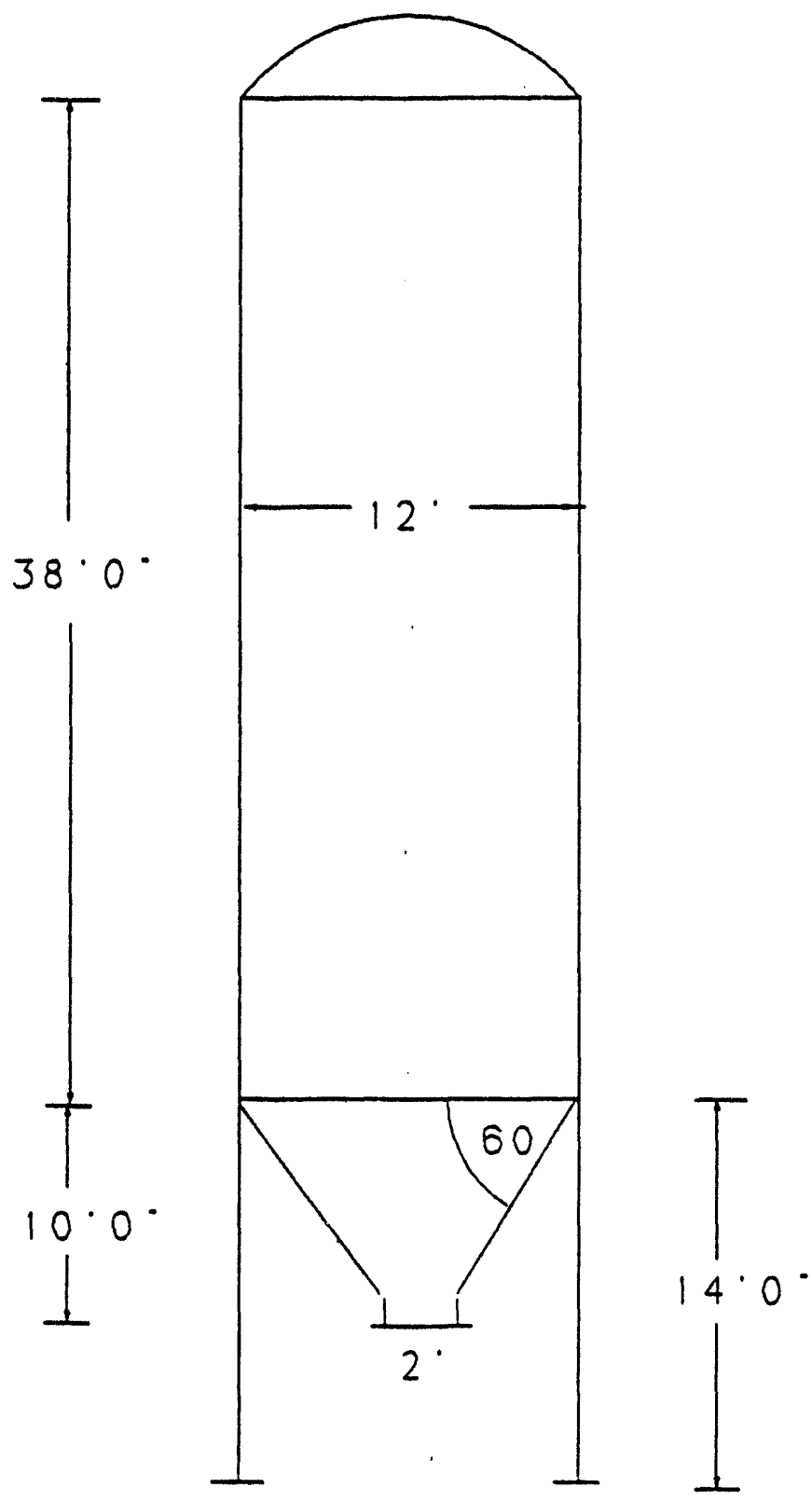

Figure A-3. Dry chemical unloading, storage and mixing system - dry chemical bulk storage silo. 
The volume of chemical fed is controlled with the rotary valve at the inlet to the weigh belt feeder. The speed at which the valve rotates will supply a controlled rate to the Weigh Belt Feeder. The set point rate required can be maintained by adjusting the speed of the rotary valve with the Weigh Belt Feeder Controller.

The silo is covered to prevent moisture from contacting the dry chemical. A vent is supplied to purge the air during truck unloading. The vent is equipped with a desiccant for moisture control.

\subsection{Weigh Belt Feeder}

A Weigh Belt Feeder is provided for an accurate mass flow rate of chemical. The weigh belt is set to supply a constant flow rate of 2 tons/day to the process. The chemical will be weighed as it enters the feeder belt; based on the weight and the speed of the belt, the mass flow rate is determined. The Weigh Belt Feeder Controller will then adjust the speed of the rotary valve accordingly to provide the specified rate. The accuracy of the weigh belt is $1 \%$.

The set point chemical flow can be varied by a process signal. For this application, the unit load will be monitored, and the flow of chemical is adjusted proportional the unit load. If another gas parameter can be measured which is representative of the chemical feed, then the chemical feed can be trimmed with a second signal.

\subsection{Dissolving Tank}

The dry chemical is conveyed to the Dissolving Tank to mix with water and form a feed solution. An agitator is furnished to assist in the mixing process. A clean supply of water is required for the dilution. A minimum flow of water is established to dilute the maximum chemical rate to $45 \%$ by weight. The dilution flow can then be held constant. If the chemical feed is reduced the \% solution will drop, and less chemical will be fed. The dissolving tank is sized for a 10 minute retention. This is adequate to supply mixing, but not too large to cause a long time delay in the adjusting of chemical feed solution. If the process is extremely sensitive to changes in feed concentration, other control schemes can be utilized. The chemical is further diluted downstream with a constant flow of $35 \mathrm{gpm}$ before injection.

The Dissolving Tank can be constructed of lined carbon steel or fiberglass. The chemical properties would require review, but normally an epoxy lining is sufficient. The tank is wrapped with electrical heating tape to maintain the solution at $200^{\circ} \mathrm{F}$ for Alternate 1 ; for 
Alternate 2 the design operating temperature is $60^{\circ} \mathrm{F}$. The downstream pumps, piping and valves are electrically heat traced for Alternate 1. Electrical tracing provides better control of the temperature. With steam tracing hot spots are created during low chemical flows, causing scale. Thus, electrical tracing was chosen for this study.

\subsection{Chemical Pumps}

The final transport of the chemical to the process is accomplished with two Chemical Feed Pumps. Both pumps are sized to supply $100 \%$ of the required chemical, and one pump serves as a spare. The required pump flow is small (approximately $2 \mathrm{gpm}$ ), and two different types of pumps can be considered.

A centrifugal pump can be used with a recycle since the flow is smaller than the flows handled with centrifugal pumps. The recycle is advantageous in that the flow is maintained through the pump, preventing possible scale of the pump during shut down.

A progressive cavity type pump can be used which feeds the solution with a screw drive. This pump can handle very high viscosity flows which may be present in this application. With either pump selection the lines should be automatically flushed upon any shutdown.

\subsection{Cost Estimate}

\subsection{Capital Costs}

Two cost estimates have been prepared for the Dry Chemical Feed System. The first estimate summarizes the system with truck delivery, and the second provides costs with the chemical delivered in bags. The two estimates are presented in Tables A-1 through A-4. The estimated Installed Costs include labor, construction materials, foundations, site preparation, engineering, and contingency.

For the bag unloading option, a storage shed has been included to provide storage of a 90 day supply of the chemical in bags. The Storage Silo has been designed for a one week supply, thus the operator must fill the silo once per week. The additional operator time for bag unloading is estimated to be 30 hours per week. 
If one silo is used in lieu of three separate silos, then a installed cost savings of $\$ 50,000$ could be attained, and the total installed cost would be $\$ 180,000$ for the truck delivery alternate.

Table A-1. Dry Chemical Feed System - Equipment Summary

Tank Truck Delivery - Alternate 1

\begin{tabular}{|c|c|c|}
\hline $\begin{array}{l}\text { Equipment } \\
\text { Item }\end{array}$ & $\begin{array}{l}\text { Physical } \\
\text { Characteristics }\end{array}$ & $\begin{array}{l}\text { Estimated } \\
\text { Cost }\end{array}$ \\
\hline Silo & $\begin{array}{c}12^{\prime} 0^{\prime \prime} \text { Dia X } 48^{\prime} 0^{\prime \prime} \mathrm{Ht} \\
\text { Carbon Steel Construction } \\
\text { Bin Vent With 2hp Motor } \\
\text { Level Controls } \\
\text { Bin Activator With 1.5 hp Motor } \\
3 \text { Supplied }\end{array}$ & $\$ 75,000$ \\
\hline Weigh Belt & $\begin{array}{l}200 \mathrm{lb} / \mathrm{hr} \text { Capacity } \\
\text { Variable Speed } 0.5 \mathrm{hp} \mathrm{Motor}\end{array}$ & $\$ 11,000$ \\
\hline Dissolving Tank & $\begin{array}{c}75 \text { Gallons } \\
\text { Lined Carbon Steel }\end{array}$ & $\$ 1,000$ \\
\hline $\begin{array}{l}\text { Tank Heating \& } \\
\text { Heat Tracing }\end{array}$ & $3 \mathrm{kw}$ & $\$ 3,000$ \\
\hline Agitator & $1 \mathrm{hp}$ & $\$ 1,000$ \\
\hline Feed Pumps & $\begin{array}{l}\text { Design Flow }=2 \text { gpm } \\
50 \text { psig Discharge Head } \\
2 \text { hp Motor }\end{array}$ & $\$ 9,000$ \\
\hline $\begin{array}{l}\text { Controls and } \\
\text { Instrumentation }\end{array}$ & & $\$ 8,000$ \\
\hline \multirow[t]{2}{*}{ Building } & $\begin{array}{c}10^{\prime} \times 20^{\prime} \times 10^{\prime} \mathrm{Ht} \\
\text { Heated }\end{array}$ & $\$ 10,000$ \\
\hline & $\begin{array}{l}\text { TOTAL EQUIPMENT COST } \\
\text { TOTAL INSTALLED COST }\end{array}$ & $\begin{array}{l}\$ 118,000 \\
\$ 250,000\end{array}$ \\
\hline
\end{tabular}


Table A-2. Dry Chemical Feed System - Equipment Summary

Tank Truck Delivery - Alternate 2

\begin{tabular}{|c|c|c|}
\hline $\begin{array}{l}\text { Equipment } \\
\text { Item }\end{array}$ & $\begin{array}{c}\text { Physical } \\
\text { Characteristics }\end{array}$ & $\begin{array}{l}\text { Estimated } \\
\text { Cost }\end{array}$ \\
\hline Silo & $\begin{array}{c}12^{\prime} 0^{\prime \prime} \text { Dia x } 48^{\prime} 0^{\prime \prime} \mathrm{Ht} \\
\text { Carbon Steel Construction } \\
\text { Bin Vent With 2hp Motor } \\
\text { Level Controls } \\
\text { Bin Activator With 1.5 hp Motor } \\
3 \text { Supplied }\end{array}$ & $\$ 75,000$ \\
\hline Weigh Belt & $\begin{array}{l}200 \mathrm{lb} / \mathrm{hr} \text { Capacity } \\
\text { Variable Speed } 0.5 \mathrm{hp} \mathrm{Motor}\end{array}$ & $\$ 11,000$ \\
\hline Dissolving Tank & $\begin{array}{l}75 \text { Gallons } \\
\text { Lined Carbon Steel }\end{array}$ & $\$ 1,000$ \\
\hline Agitator & $1 \mathrm{hp}$ & $\$ 1,000$ \\
\hline Feed Pumps & $\begin{array}{c}\text { Design Flow }=2 \text { gpm } \\
50 \text { psig Discharge Head } \\
2 \text { hp Motor }\end{array}$ & $\$ 9,000$ \\
\hline $\begin{array}{l}\text { Controls and } \\
\text { Instrumentation }\end{array}$ & & $\$ 8,000$ \\
\hline \multirow[t]{2}{*}{ Building } & $\begin{array}{c}10^{\prime} \times 20^{\prime} \times 10^{\prime} \mathrm{Ht} \\
\text { Heated }\end{array}$ & $\$ 10,000$ \\
\hline & $\begin{array}{l}\text { TOTAL EQUIPMENT COST } \\
\text { TOTAL INSTALLED COST }\end{array}$ & $\begin{array}{l}\$ 115,000 \\
\$ 244,000\end{array}$ \\
\hline
\end{tabular}


Table A-3. Dry Chemical Feed System - Equipment Summary Bag Delivery - Alternate 1

\begin{tabular}{|c|c|c|}
\hline $\begin{array}{l}\text { Equipment } \\
\text { Item }\end{array}$ & $\begin{array}{c}\text { Physical } \\
\text { Characteristics }\end{array}$ & $\begin{array}{l}\text { Estimated } \\
\text { Cost }\end{array}$ \\
\hline Bag Unloading & $\begin{array}{l}\text { Bag Dump Station With } \\
\text { Dust Collector and Hood } \\
\text { Bag Splitter Shelf } \\
\text { Screw Conveyor }\end{array}$ & $\$ 10,000$ \\
\hline $\begin{array}{l}\text { Storage } \\
\text { Warehouse }\end{array}$ & $52^{\prime} \times 52^{\prime} \times 15^{\prime}$ & $\$ 30,000$ \\
\hline Silo & $\begin{array}{c}8^{\prime} 0^{\prime \prime} \text { Dia x } 30^{\prime} 0^{\prime \prime} \mathrm{Ht} \\
\text { Carbon Steel Construction } \\
\text { Bin Vent With } 2 \mathrm{hp} \text { Motor } \\
\text { Bin Activator With 1.5 hp Motor }\end{array}$ & $\$ 15,000$ \\
\hline Weigh Belt & $\begin{array}{l}200 \mathrm{lb} / \mathrm{hr} \text { Capacity } \\
\text { Variable Speed } 0.5 \mathrm{hp} \text { Motor }\end{array}$ & $\$ 11,000$ \\
\hline Dissolving Tank & $\begin{array}{c}75 \text { Gallons } \\
\text { Lined Carbon Steel }\end{array}$ & $\$ 1,000$ \\
\hline $\begin{array}{l}\text { Tank Heating and } \\
\text { Heat Tracing }\end{array}$ & $3 \mathrm{kw}$ & $\$ 3,000$ \\
\hline Agitator & $1 \mathrm{hp}$ & $\$ 1,000$ \\
\hline Feed Pumps & $\begin{array}{l}\text { Design Flow }=2 \text { gpm } \\
50 \text { psig Discharge head } \\
2 \text { hp Motor }\end{array}$ & $\$ 9,000$ \\
\hline \multirow[t]{2}{*}{$\begin{array}{l}\text { Controls and } \\
\text { Instrumentation }\end{array}$} & & $\$ 8.000$ \\
\hline & $\begin{array}{l}\text { TOTAL EQUIPMENT COST } \\
\text { TOTAL INSTALLED COST }\end{array}$ & $\begin{array}{r}\$ 88,000 \\
\$ 190,000\end{array}$ \\
\hline
\end{tabular}


Table A-4. Dry Chemical Feed System - Equipment Summary

Bag Delivery - Alternate 2

\begin{tabular}{|c|c|c|}
\hline $\begin{array}{l}\text { Equipment } \\
\text { Item }\end{array}$ & $\begin{array}{c}\text { Physical } \\
\text { Characteristics }\end{array}$ & $\begin{array}{c}\text { Estimated } \\
\text { Cost }\end{array}$ \\
\hline Bag Unloading & $\begin{array}{l}\text { Bag Dump Station With } \\
\text { Dust Collector and Hood } \\
\text { Bag Splitter Shelf } \\
\text { Screw Conveyor }\end{array}$ & $\$ 10,000$ \\
\hline $\begin{array}{l}\text { Storage } \\
\text { Warehouse }\end{array}$ & $52^{\prime} \times 52^{\prime} \times 15^{\prime}$ & $\$ 30,000$ \\
\hline Silo & $\begin{array}{c}8^{\prime} 0^{\prime \prime} \text { Dia x } 30^{\prime} 0 " \mathrm{Ht} \\
\text { Carbon Steel Construction } \\
\text { Bin Vent With } 2 \text { hp Motor } \\
\text { Bin Activator With } 1.5 \text { hp Motor }\end{array}$ & $\$ 15,000$ \\
\hline Weigh Belt & $\begin{array}{l}200 \mathrm{lb} / \mathrm{hr} \text { Capacity } \\
\text { Variable Speed } 0.5 \mathrm{hp} \text { Motor }\end{array}$ & $\$ 11,000$ \\
\hline Dissolving Tank & $\begin{array}{c}75 \text { Gallons } \\
\text { Lined Carbon Steel }\end{array}$ & $\$ 1,000$ \\
\hline Agitator & $1 \mathrm{hp}$ & $\$ 1,000$ \\
\hline Feed Pumps & $\begin{array}{l}\text { Design Flow }=2 \mathrm{gpm} \\
50 \text { psig Discharge head } \\
2 \text { hp Motor }\end{array}$ & $\$ 9,000$ \\
\hline \multirow{2}{*}{$\begin{array}{l}\text { Controls and } \\
\text { Instrumentation }\end{array}$} & & $\$ 8.000$ \\
\hline & $\begin{array}{l}\text { TOTAL EQUIPMENT COST } \\
\text { TOTAL INSTALLED COST }\end{array}$ & $\begin{array}{r}\$ 83,000 \\
\$ 184,000\end{array}$ \\
\hline
\end{tabular}




\subsection{Operating Costs}

The operation of this system requires manpower, electrical power, and chemical consumption. Estimates have been prepared for each of these parameters and are summarized below in Table A-5.

Table A-5. Operating Parameters

\begin{tabular}{||lcccc||}
\hline & \multicolumn{2}{c}{ Truck Delivery } & \multicolumn{2}{c|}{ Bag Delivery } \\
& Alt 1 & Alt 2 & Alt 1 & Alt 2 \\
\hline Manpower & $28 \mathrm{hr} / \mathrm{week}$ & $28 \mathrm{hr} /$ week & $58 \mathrm{hr} /$ week & $58 \mathrm{hr} /$ week \\
Electrical Load & $13.5 \mathrm{kw}$ & $10.5 \mathrm{kw}$ & $8 \mathrm{kw}$ & $5 \mathrm{kw}$ \\
Chemical Used & 2 ton/day & 2 ton/day & 2 ton/day & 2 ton/day \\
\hline
\end{tabular}




\subsection{Operating Costs}

The operation of this system requires manpower, electrical power, and chemical consumption. Estimates have been prepared for each of these parameters and are summarized below in Table A-5.

Table A-5. Operating Parameters

\begin{tabular}{|lcccc||}
\hline & \multicolumn{2}{c}{ Truck Delivery } & \multicolumn{2}{c|}{ Bag Delivery } \\
& Alt 1 & Alt 2 & Alt 1 & Alt 2 \\
\hline Manpower & $28 \mathrm{hr} /$ week & $28 \mathrm{hr} /$ week & $58 \mathrm{hr} /$ week & $58 \mathrm{hr} /$ week \\
Electrical Load & $13.5 \mathrm{kw}$ & $10.5 \mathrm{kw}$ & $8 \mathrm{kw}$ & $5 \mathrm{kw}$ \\
Chemical Used & 2 ton/day & 2 ton/day & 2 ton/day & 2 ton/day \\
\hline
\end{tabular}




\section{Appendix B - Liquid Chemical Delivery, Storage and Handling System Description and Cost Estimates}

\subsection{Scope}

The Liquid Chemical Feed System is designed to receive a chemical solution delivered by truck with a concentration of $20 \%$ or $45 \%$. The solution is stored and fed to the process at a controlled rate, as shown in Figure B-1. The equipment required to handle the chemical feed is detailed on the Equipment Summary attached at the end of this report. The system includes all equipment and controls necessary for the feed of the chemical from the truck unloading to the discharge of the feed pumps.

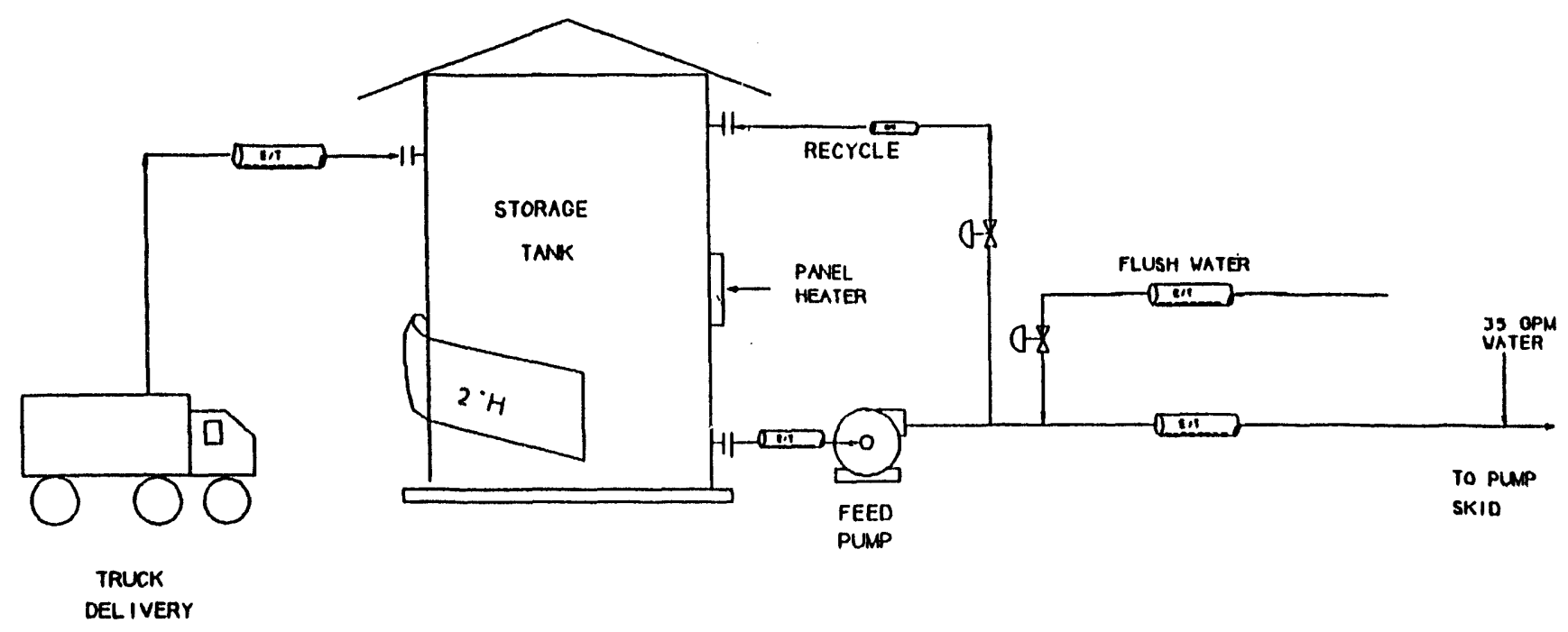

Figure B-1. Liquid chemical unloading, storage and mixing system. 


\subsection{Design Basis}

The following criteria has been established for the design of this system:

$\begin{array}{ll}\begin{array}{l}\text { Chemical Feed Rate } \\ \text { Bulk Density }\end{array} & \begin{array}{l}2 \text { tons } / \text { day } \\ 0.3 \text { to } 0.5 \mathrm{gm} / \mathrm{cc}\end{array} \\ 45 \% \text { Solution Feed } & \begin{array}{l}35 \mathrm{gal} / \mathrm{hr} \\ \text { (Mixed with } 35 \mathrm{gpm} \text { water) }\end{array} \\ \begin{array}{l}95 \mathrm{gal} / \mathrm{hr} \\ \text { (Mixed with } 35 \mathrm{gpm} \text { water) }\end{array} \\ \text { Storage Required } & 90 \text { days } \\ \text { Minimum Temperature } & 200^{\circ} \mathrm{F} \text { (Alternate 1) } \\ \text { Chemical Delivery } & 60^{\circ} \mathrm{F} \text { (Alternate 2) }\end{array}$

Some chemicals may require heating to $200^{\circ} \mathrm{F}$ to remain in solution or to control viscosity. Alternate 1 provides sufficient process heating and heat tracing to keep the solution at $200^{\circ} \mathrm{F}$. Alternate 2 assumes that no process heating is required; however heat tracing has been provided to prevent freezing and to allow viscosity control by heating up to $60^{\circ} \mathrm{F}$.

\subsection{System Description}

\subsection{Truck Delivery}

The system is designed to receive truck load quantities of the chemical solution. The shipping limit for the truck transport on highways is $40,000 \mathrm{lbs}$, and the system is designed on this basis. The quantity of chemical shipped is approximately 4,500 gallons per truckload. The truck is pressurized with air to transport the chemical from the truck to the Storage Tank. A flexible hose connection is provided for the truck hookup; the transport piping from the truck hookup to the top of the tank is hard piped. A relief valve is supplied on the truck to prevent overpressure of the truck during the transport operation. The tank has a vent to purge the motive air to atmosphere minimizing back pressure. A high level alarm and high-high level alarm are provided on the tank to alarm the operator as the tank fills. The high alarm is set at $2 \mathrm{ft}$ from the top while the high-high alarm is set at $1 \mathrm{ft}$ from the top. The level signal can be transmitted for remote monitoring, if desired. The high-high level can also shut off the air supply. 
Normally the truck unloading continues until the truck is emptied. The truck is weighed entering and leaving to determine the quantity of chemical delivered.

\subsection{Storage Tank}

As shown on Figure B-1, the chemical solution is stored in a tank and then supplied to a transfer Pump for feed to the process. The Storage Tank is constructed of carbon steel, and has been sized to hold 90 days of chemical at a feed rate of 2 tons/day. The Tank size is $31^{\prime} 0 "$ Diameter X 40'0" Ht for $20 \%$ solution or $25^{\prime} 0$ " Diameter X 25' $0^{\prime \prime} \mathrm{Ht}$ for $45 \%$ solution.

The tank is furnished with a level indicator and level transmitter. To prevent crystallization of the chemical, the tank is heated with a electrical panel heater for Alternate 1. The heater is sized to keep the chemical solution above $200^{\circ} \mathrm{F}$.

\subsection{Chemical Pumps}

The final transport of the chemical to the process is accomplished with two Chemical Feed Pumps. Both pumps are sized to supply $100 \%$ of the required chemical, and one pump serves as a spare. The required pump flow is small (approximately $2 \mathrm{gpm}$ ), and two different types of pumps can be considered.

A centrifugal pump can be used with a recycle since the flow is smaller than the flows handled with centrifugal pumps. The recycle is advantageous in that the flow is maintained through the pump, preventing possible scale of the pump during shut down.

A progressive cavity type pump can be used which feeds the solution with a screw drive. This pump can handle very high viscosity flows which may be present in this application. With either pump selection the lines should be automatically flushed upon any shutdown.

The flow rate is controlled by adjusting the recycle flow control valve. The unit load will be monitored and the control valve will be adjusted proportional to the unit load. 


\subsection{Cost Estimate}

\subsection{Capital Costs}

Two cost estimates have been prepared for the Liquid Chemical Feed System (Alternate 1). The first estimate, summarized on Table B-1, is for storage of $20 \%$ solution. Table B-3 details the cost for $45 \%$ solution. Additionally, Tables B-2 and B-4 detail the costs for the $20 \%$ and $45 \%$ solution systems, respectively, for Alternate 2 in which heat tracing only is required. The estimated Installed Costs include labor, construction materials, foundations, site preparation, and contingency.

\subsection{Operating Costs}

The operation of this system requires manpower, electrical power, and chemical consumption. Estimates have been prepared for these parameters and are summarized in Table B-5. The estimates are the same for either $20 \%$ solution or $45 \%$ solution, except for the heating load.

Table B-1. Liquid Chemical Feed System - Equipment Summary 20\% Solution - Alternate 1 (Process Heating to $200^{\circ} \mathrm{F}$ )

\begin{tabular}{|c|c|c|}
\hline $\begin{array}{l}\text { Equipment } \\
\text { Item }\end{array}$ & $\begin{array}{l}\text { Physical } \\
\text { Characteristics }\end{array}$ & $\begin{array}{l}\text { Estimated } \\
\text { Cost }\end{array}$ \\
\hline Tank & $\begin{array}{c}31^{\prime} 0^{\prime \prime} \mathrm{Dia} \times 40^{\prime} 0^{\prime \prime} \mathrm{Ht} \\
\text { Carbon Steel }\end{array}$ & $\$ 30,000$ \\
\hline $\begin{array}{l}\text { Tank Heating and } \\
\text { Heat Tracing }\end{array}$ & $96.5 \mathrm{kw}$ & $\$ 20,000$ \\
\hline Feed Pumps & $\begin{array}{c}\text { Design Flow }=2 \mathrm{gpm} \\
50 \text { psig Discharge Head } \\
2 \mathrm{hp} \mathrm{Motor} \\
\text { Two Supplied }\end{array}$ & $\$ 9,000$ \\
\hline \multirow[t]{2}{*}{ Building } & $\begin{array}{l}2^{\prime} \times 4^{\prime} \times 8^{\prime} \mathrm{Ht} \\
\text { Heated }\end{array}$ & $\$ 1,000$ \\
\hline & $\begin{array}{l}\text { TOTAL EQUIPMENT COST } \\
\text { TOTAL INSTALLED COST }\end{array}$ & $\begin{array}{r}\$ 60,000 \\
\$ 127,000\end{array}$ \\
\hline
\end{tabular}


Table B-2. Liquid Chemical Feed System - Equipment Summary 20\% Solution - Alternate 2 (Heat Tracing Only)

\begin{tabular}{|c|c|c|}
\hline $\begin{array}{l}\text { Equipment } \\
\text { Item }\end{array}$ & $\begin{array}{c}\text { Physical } \\
\text { Characteristics }\end{array}$ & $\begin{array}{l}\text { Estimated } \\
\text { Cost }\end{array}$ \\
\hline Tank & $\begin{array}{c}31^{\prime} 0 " \text { Dia } \times 40^{\prime} 0 " \mathrm{Ht} \\
\text { Carbon Steel }\end{array}$ & $\$ 30,000$ \\
\hline Feed Pumps & $\begin{array}{c}\text { Design Flow }=2 \mathrm{gpm} \\
50 \text { psig Discharge Head } \\
2 \text { hp Motor } \\
\text { Two Supplied }\end{array}$ & $\$ 9,000$ \\
\hline \multirow[t]{2}{*}{ Building } & $\begin{array}{l}2^{\prime} \times 4^{\prime} \times 8^{\prime} \mathrm{Ht} \\
\text { Heated }\end{array}$ & $\$ 1,000$ \\
\hline & $\begin{array}{l}\text { TOTAL EQUIPMENT COST } \\
\text { TOTAL INSTALLED COST }\end{array}$ & $\begin{array}{l}\$ 40,000 \\
\$ 85,000\end{array}$ \\
\hline
\end{tabular}

Table B-3. Liquid Chemical Feed System - Equipment Summary 45\% Solution - Alternate 1 (Process Heating to $200^{\circ} \mathrm{F}$ )

\begin{tabular}{|c|c|c|}
\hline $\begin{array}{l}\text { Equipment } \\
\text { Item }\end{array}$ & $\begin{array}{l}\text { Physical } \\
\text { Characteristics }\end{array}$ & $\begin{array}{c}\text { Estimated } \\
\text { Cost }\end{array}$ \\
\hline Tank & $\begin{array}{c}25^{\prime} 0 " \text { Dia x 25'0" Ht } \\
\text { Carbon Steel }\end{array}$ & $\$ 18,000$ \\
\hline $\begin{array}{l}\text { Tank Heating and } \\
\text { Heat Tracing }\end{array}$ & $53 \mathrm{kw}$ & $\$ 12,000$ \\
\hline Feed Pumps & $\begin{array}{c}\text { Design Flow }=2 \mathrm{gpm} \\
50 \text { psig Discharge Head } \\
2 \text { hp Motor } \\
\text { Two Supplied }\end{array}$ & $\$ 9,000$ \\
\hline \multirow[t]{2}{*}{ Building } & $\begin{array}{c}3^{\prime} \times 4^{\prime} \times 8^{\prime} \mathrm{Ht} \\
\text { Heated }\end{array}$ & $\$ 1,000$ \\
\hline & $\begin{array}{l}\text { TOTAL EQUIPMENT COST } \\
\text { TOTAL INSTALLED COST }\end{array}$ & $\begin{array}{l}\$ 40,000 \\
\$ 85,000\end{array}$ \\
\hline
\end{tabular}


Table B-4. Liquid Chemical Feed System - Equipment Summary 45\% Solution - Alternate 2 (Heat Tracing Only)

\begin{tabular}{|c|c|c|}
\hline $\begin{array}{l}\text { Equipment } \\
\text { Item }\end{array}$ & $\begin{array}{l}\text { Physical } \\
\text { Characteristics }\end{array}$ & $\begin{array}{l}\text { Estimated } \\
\text { Cost }\end{array}$ \\
\hline Tank & $\begin{array}{l}25^{\prime} 0 " \text { Dia } \times 22^{\prime} 0 " \text { Ht } \\
\text { Carbon Steel }\end{array}$ & $\$ 18,000$ \\
\hline Feed Pumps & $\begin{array}{c}\text { Design Flow }=2 \text { gpm } \\
50 \text { psig Discharge Head } \\
2 \text { hp Motor } \\
\text { Two Supplied }\end{array}$ & $\$ 9,000$ \\
\hline \multirow[t]{2}{*}{ Building } & $\begin{array}{l}3^{\prime} \times 4^{\prime} \times 8^{\prime} \mathrm{Ht} \\
\text { Heated }\end{array}$ & $\$ 1.000$ \\
\hline & $\begin{array}{l}\text { TOTAL EQUIPMENT COST } \\
\text { TOTAL INSTALLED COST }\end{array}$ & $\begin{array}{l}\$ 28,000 \\
\$ 60,000\end{array}$ \\
\hline
\end{tabular}

Table B-5. Operating Parameters

\begin{tabular}{|lccccc||}
\hline & \multicolumn{2}{c}{$20 \%$ Solution } & \multicolumn{2}{c|}{$45 \%$ Solution } \\
& Alt 1 & Alt 2 & Alt 1 & Alt 2 \\
\hline Manpower & $10 \mathrm{hr} /$ week & $10 \mathrm{hr} /$ week & $10 \mathrm{hr} /$ week & $10 \mathrm{hr} /$ week \\
Electrical & Max & $97 \mathrm{kw}$ & $1.5 \mathrm{kw}$ & $54.5 \mathrm{kw}$ & $1.5 \mathrm{kw}$ \\
Load & Ave & $58 \mathrm{kw}$ & $1 \mathrm{kw}$ & $33.5 \mathrm{kw}$ & $1 \mathrm{kw}$ \\
Chemical Used & 2 ton/day & 2 ton/day & 2 ton/day & 2 ton/day \\
\hline
\end{tabular}




\section{Appendix C - Pump Skids and Injection Lances/Piping System Description and Cost Estimates}

\subsection{Scope}

The Pump Skids and Injection Lances/Piping System is designed to receive a chemical that is mixed to the proper concentration, dilute further the solutions with water, meter and inject the chemical solution into the flue gas ductwork upstream of the precipitator.

\subsection{Design Basis}

The following criteria has been established for the design of this system:

$$
\text { Total } \mathrm{H}_{2} \mathrm{O} / \text { Solution Feed Rate } \quad 35 \mathrm{gal} / \mathrm{min} \text {. }
$$

Chemical Delivery

Pumped from Chemical Mixing/Preparation System

Heat tracing of all piping is provided to prevent freezing and to allow viscosity control by heating up to $60^{\circ} \mathrm{F}$; or alternatively, $200^{\circ} \mathrm{F}$ for one chemical requiring such temperatures.

\subsection{System Description}

Figure $\mathrm{C}-1$ is a schematic of the pump skid, piping and injection lance system assumed for this study. Figure C-2 is a detailed schematic of piping for one of the four metering pumps with which the skid is equipped. This system is the same as or similar to those used for other proprietary chemical injection processes and forms the basis for the capital cost estimate used in this analysis. In fact the system depicted here was actually used for a trial injection of proprietary chemical on a $250 \mathrm{MW}$ unit in the Eastern U.S.

As shown in these figures, the chemical solution is pumped to the skid at a controlled feed rate. The pump skid has the capability to admix additional water for a constant total throughput of chemical/water solution of $35 \mathrm{gpm}$. The four metering pumps are adjustable and can be calibrated to supply the correct federate to each separate piping/injection lance circuit. 


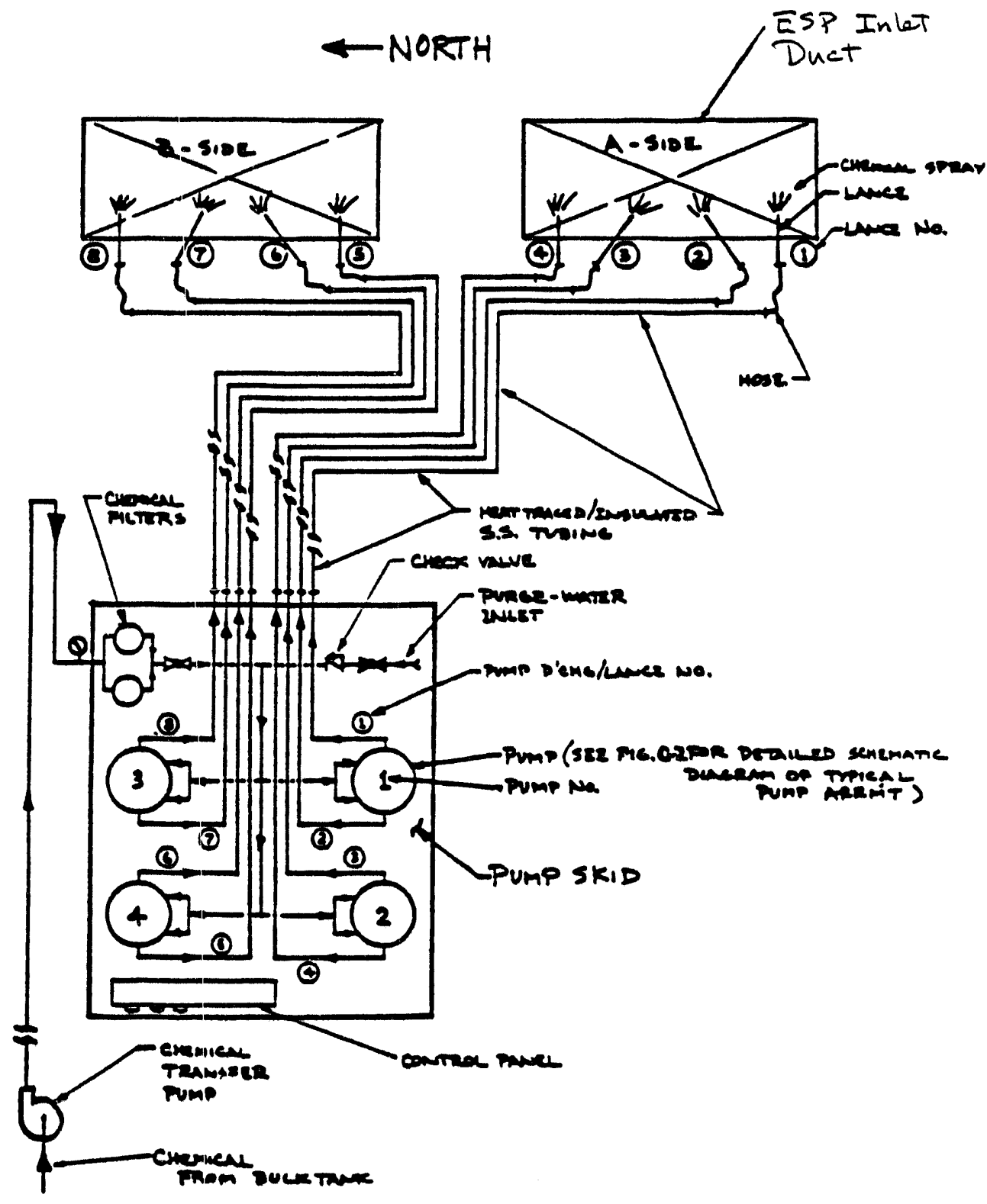

Figure C-1. Piping and pump skid schematic (based on similar proprietary chemical injection systems). 


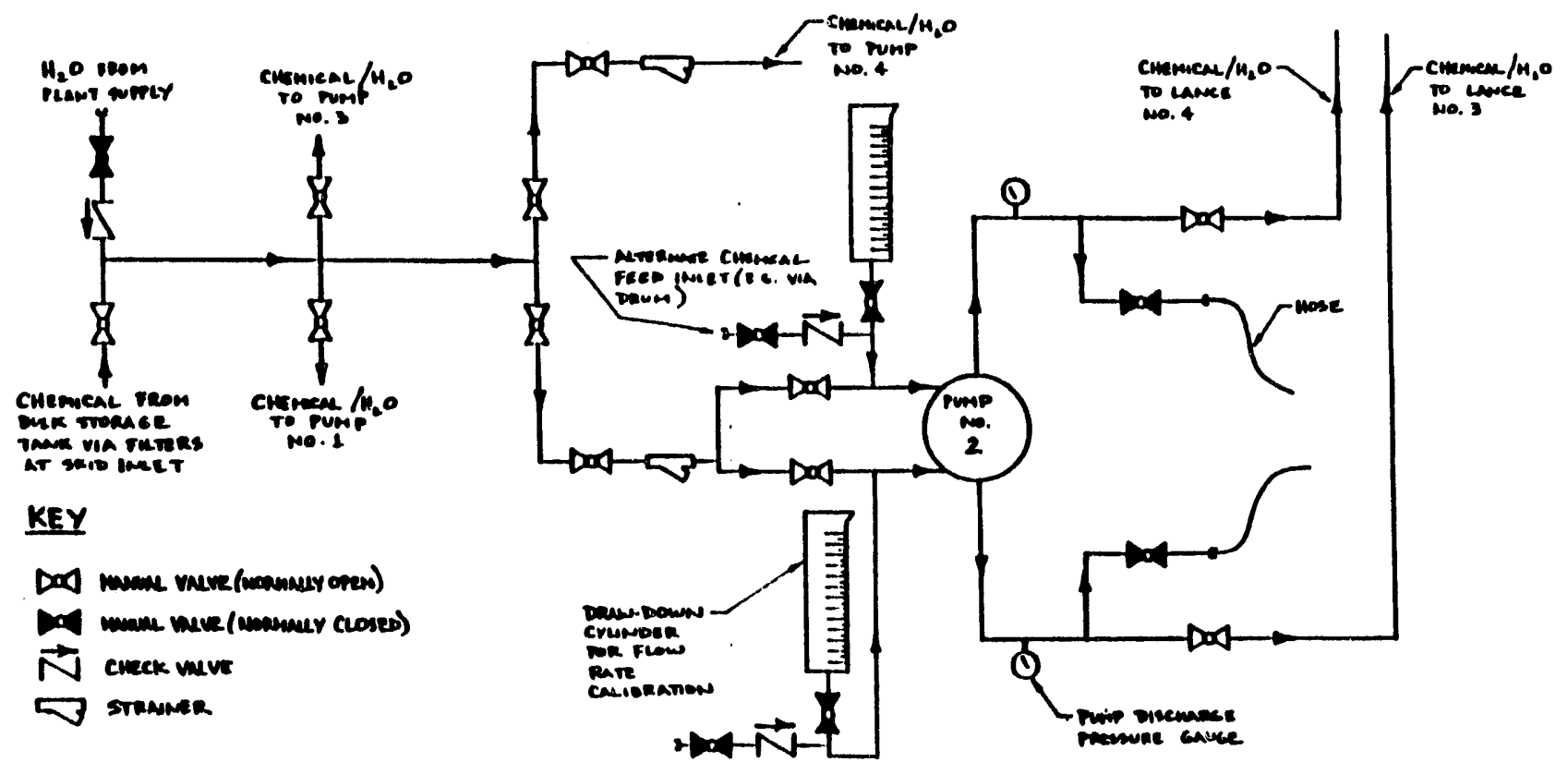

Figure C-2. Detailed schematic of pump skid piping for one pump (based on similar proprietary chemical injection systems). 
The injection lances and piping are heat traced to provide the proper temperature for freeze protection, process heating and/or viscosity control as needed. The particular lances used for the illustrated system used compressed air for atomization and injection of the solution.

\subsection{Cost Estimate}

The capital cost for the pump skid and piping/injection lance system was developed based on actual costs of the system depicted in Figures C-1 and C-2. The total installed cost for this analysis is estimated to be $\$ 66,200$.

In preliminary economic comparisons for this study, power usage costs for the other components of the total chemical unloading, storage and mixing system proved negligible compared to chemical and the capital equipment costs. Since this study involves a differential cost method and the pump skid/piping and lance system power usage is even smaller, such costs were not developed for this analysis. O\&M costs were assumed to be included with the $O \& M$ costs for the other components of the total chemical unloading, storing and mixing system. 


\section{Conclusions and Recommendations}

\section{Bench-Scale Testing Conclusions:}

- Additives "C" and "D" were found to decrease particle emissions from the bench-scale ESP. The measures of success identified for the bench-scale phase of the program have been surpassed.

- Microscopic examination of fly ash samples indicate the agglomeration of fine particles when additives are used.

- Preliminary chemical analysis indicates that the fly ash is non-hazardous.

- Preliminary economic analysis shows that additive "C" is cost competitive with other additive technologies and with adding ESP capacity.

\section{Recommendations}

- Perform pilot-scale testing to evaluate additives " $\mathrm{C}$ " and " $\mathrm{D}$ " at conditions more representative of a full-scale ESP.

- Perform the pilot-scale evaluation in order to gather data that will refine the cost estimates for the technology.

- Perform the pilot-scale evaluation in a way that provides information on additive performance across a range of ESP operating conditions. 

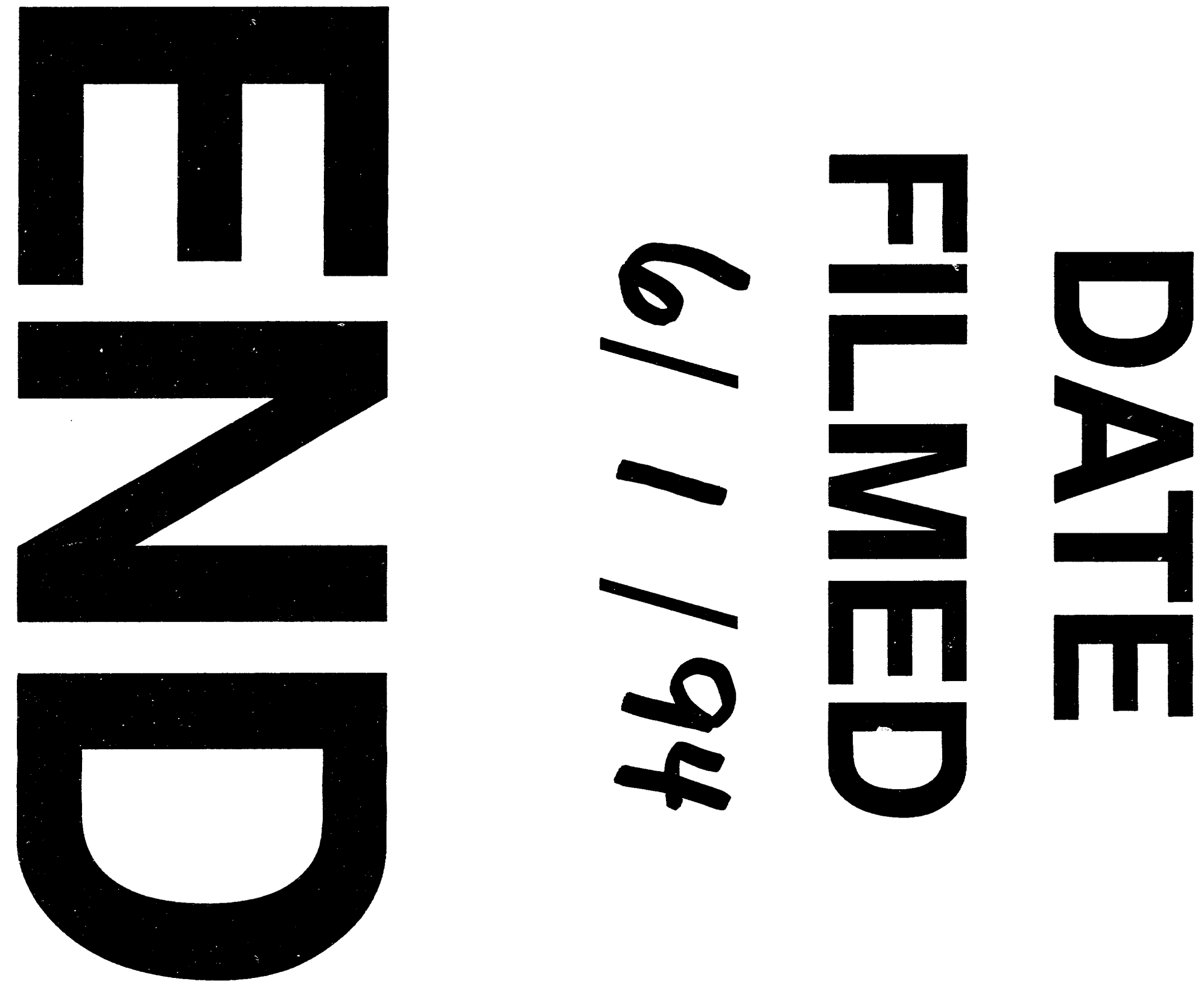
